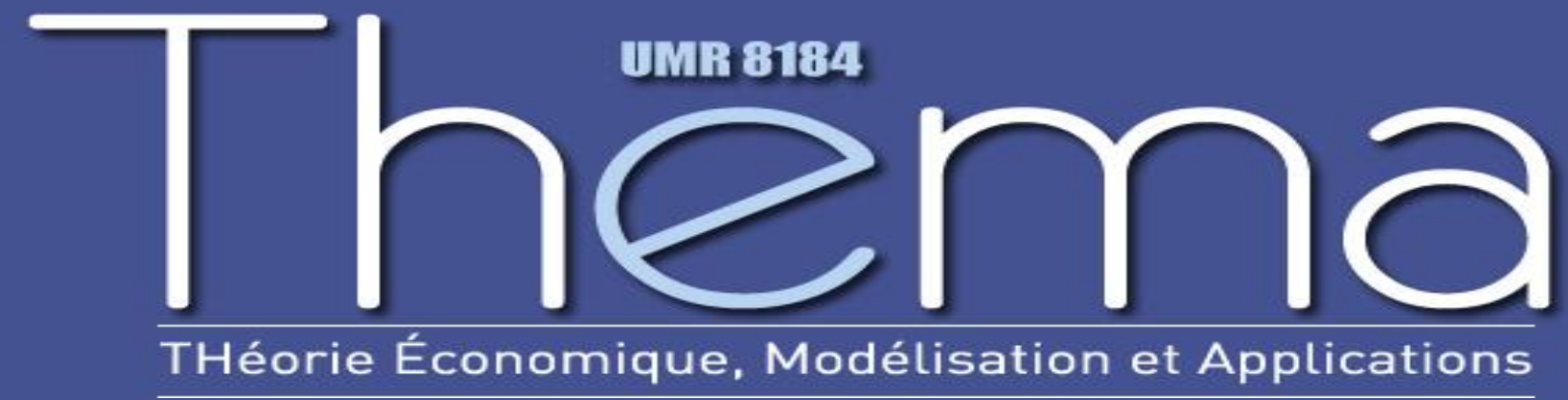

Thema Working Paper $\mathrm{n}^{\circ}$ 2011-03

Université de Cergy Pontoise, France

Product market regulation, firm size, unemployment and informality in developing economies

Charlot Olivier

Malherbet Franck

Terra Cristina

January, 2011 


\title{
Product market regulation, firm size, unemployment and informality in developing economies*
}

\author{
Olivier Charlot† Franck Malherbet ${ }^{\ddagger}$ and Cristina Terra ${ }^{\S}$
}

January 2011

\begin{abstract}
This paper studies the impact of product and labor market regulations on informality and unemployment in a general framework where formal and informal firms are subject to the same externalities, differing only with respect to some parameter values. Both formal and informal firms have monopoly power in the goods market, they are subject to matching friction in the labor market, and wages are determined through bargaining between large firms and their workers. The informal sector is found to be endogenously more competitive than the formal one. We find that lower strictness of product or labor market regulations lead to a simultaneous reduction in informality and unemployment. The difference between these two policy options lies on their effect on wages. Lessening product market strictness increases wages in both sector but also increases the formal sector wage premium. The opposite is true for labor market regulation. Finally, we show that the so-called overhiring externality due to wage bargaining translates into a smaller relative size of the informal sector.
\end{abstract}

Keywords Informality; Product and Labor Market Imperfections; Firm Size

JEL Classification E24; E26; J60; L16; O1

\footnotetext{
*We thank Pedro Miguel Olea de Souza e Silva for excellent research assistance. We also thank participants from PET'10 Conference and from seminars at THEMA-Université de Cergy-Pontoise, GAINS-Université du Maine, ERMES-Université Paris II, BETA-Université de Strasbourg and CEPII for comments and suggestions. The usual disclaimer applies.

${ }^{\dagger}$ Université de Cergy-Pontoise, THEMA, F-95000 Cergy-Pontoise, and CIRPEE. Email: ocharlot@u-cergy.fr

${ }^{\ddagger}$ Université de Rouen, CECO - Ecole Polytechnique, fRDB and IZA.

${ }^{\S}$ Université de Cergy-Pontoise, THEMA; Graduate School of Economics, Fundaçao Getulio Vargas; and CEPII.
} 


\section{Introduction}

Informal activities are pervasive in both developed and developing economies. According to Schneider and Enste (2000) estimates, the size of the shadow economy as a percentage of GDP ranges from 25 to $60 \%$ in Latin America, from 13 to $50 \%$ in Asia, and it is around $15 \%$ among OECD countries, reaching $30 \%$ in some European countries. Informal firms differ from formal ones in a number of measurable characteristics, and there is a growing literature trying to understand the causes of informality and its differences from formal businesses.

In developing countries, in particular, informality seems to be omnipresent in virtually all sectors of the economy. In Brazil, about $60 \%$ of all food-retailing market is operated by informal marketplaces, and about one third of all processed meat comes from informal businesses. Similar ratios are found in audiovisual and software sector, pharmaceutical industry, gasoline retailing, and so on (see Capp and Jones, 2005). We take the view that, in developing countries, informal firms should be taken as being subject to the same economic environment and they should face the same externalities as the formal ones, except, of course, for the fact that informal firms do not comply with taxes and regulations.

In this spirit, we propose a general framework where formal and informal firms are equal in all aspects, except for the value of some exogenous parameters related to labor market matching technology, productivity, workers' bargaining power and, evidently, entry costs and labor taxes. Our numerical simulation is successful in replicating the key characteristics of the Brazilian economy. We study the effects of changes in product market regulation (PMR) modeled as changes in entry costs in the formal sector, and of changes in labor market regulation (LMR), proxied by changes in workers' bargaining power, on the main endogenous variables of the model. We find that a fall in PMR strictness reduces unemployment and the size of the informal sector while it raises wages. A fall in LMR, on its turn, also reduces both unemployment and informality, but it reduces wages.

One noteworthy feature of our model is that the number and size of firms are endogenously determined. Our model endogenously generates a more competitive informal sector, which is in line with empirical evidence. Moreover, we show that both a fall in PMR and in LMR render the formal sector closer to the informal one in terms of competitiveness.

We chose Brazil as our benchmark case since it is a developing economy with a large informal sector. Brazil's informal sector employs around $40 \%$ of its labor force, while the country's unemployment rate ranged from $7 \%$ to $13 \%$ over the last decade. Moreover, Brazil has relatively high barriers to entry in the product market (Djankov et al., 2002), while labor legislations appear relatively moderate compared to some other Latin American countries (Botero et al., 
2004). In this perspective, it is interesting to examine how unemployment and informality would react, had the government chosen a different mix between product and labor market regulations, that is, lower barriers to entry and/or stricter labor regulations.

There is a recent and growing literature on unemployment and informality in developing countries. Our analysis considers distortions that have not yet been contemplated by previous models as being shared by both formal and informal sectors. In sum, in our model: (i) there are frictions in both formal and informal labor markets; (ii) job seekers are identical and can find jobs in both sectors, that is, the labor market is not segmented; (iii) the number and size of firms in each sector is endogenous, which renders market power also endogenous; (iv) wages are set through bargaining between large firms and their workers, which generates externalities in the two sectors.

It is worth highlighting that, with respect to the labor market, we consider two sources of distortions. First, there are the standard congestion externalities linked to the matching process. Second, there are distortions resulting from wage bargaining between firms and workers, which may generate either over- or underhiring. These wage bargaining distortions were not considered in previous literature on informality. The size of overhiring is related to workers bargaining power and to the price elasticity of demand faced by firms. Since those two features are allowed to differ across sectors, the size of the overhiring externality itself may vary across sectors. Our numerical exercises indicate that overhiring takes place in the formal sector, while there is underhiring in the informal sector. This translates into a smaller relative size of the informal sector compared to the case without overhiring.

Following Blanchard and Giavazzi (2003), a number of recent papers have studied the impact of PMR and LMR on unemployment in economies with frictions in the labor market (e.g. Delacroix, 2006, Ebell and Haefke, 2009, Felbermayr and Prat, 2010). Those studies, however, do not consider the existence of an informal sector. Given that informality represents a large share of the economies, it is important to understand the impacts of policies on the informal sector as well. For instance, the relative size of the informal sector should be responsive to changes in the costs involved into creating a new business, since many of such costs are avoided by firms entering the informal sector. Indeed, Figure 1 below illustrates that, among Latin American countries, the informal sector tends to be larger in countries where barriers to entry are stricter. Many developing countries tend to have relatively larger barriers to entry of new businesses (see Djankov et al., 2002), which could be part of the explanation of informality being more pervasive among those countries.

The economic literature on informality has recently turned its attention to search and match- 


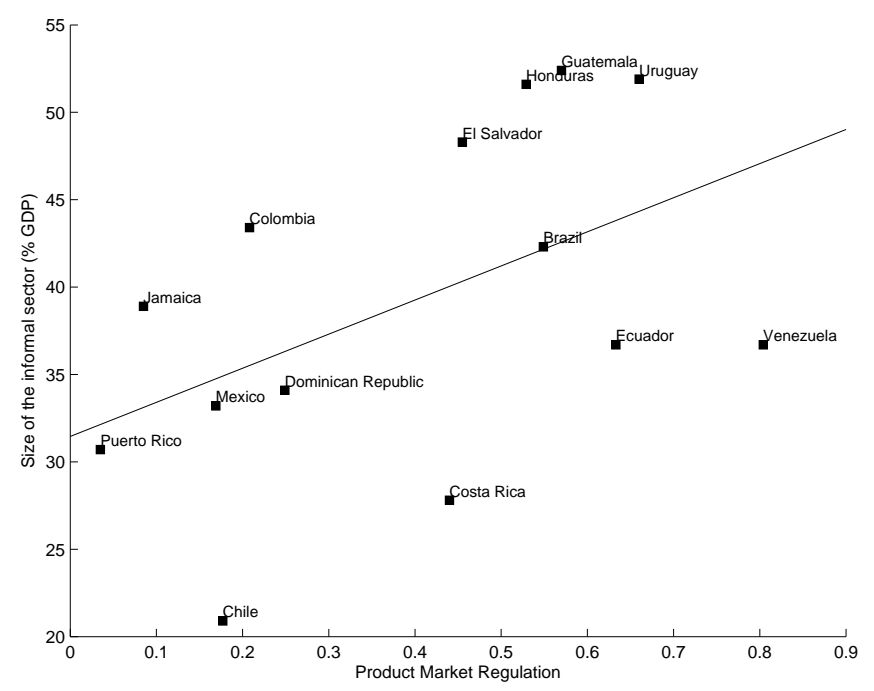

Figure 1: Informality and PMR in developing countries

ing models. Zenou (2008) studies the impact of labor market policies on informality, and he models the formal sector as subject to labor market frictions and presenting unemployment, while the informal one is taken as being competitive. Although it is generally acknowledged that one of the advantages of the informal sector relies on the fact that finding a job is easier, there is at best no appealing evidence that the informal labor market should be a fully competitive one. In any case, this particular case can easily be embedded in a more general model incorporating matching frictions in both formal and informal labor markets, as the one developed in this paper.

In Fugazza and Jacques (2004), there are search frictions in both sectors, but they are still segmented. Workers are not allowed to seek for jobs in the formal and informal sectors simultaneously, and they differ with respect to a 'moral' cost of working in the informal sector. In the case of developing countries, there is evidence that the informal sector is a integral part of the economy, rather than a residual sector in a segmented labor market. Based on the Latin American experience, Maloney (2004) claims that the informal sector should be viewed as an unregulated micro-entrepreneurial sector instead. In terms of the unemployed's behavior, for instance, job seekers in developing countries are likely to look simultaneously for formal and informal jobs, either because they cannot afford to do otherwise, or because there is less social stigma related to taking a job in the informal sector. In contrast, in more developed countries workers look for a job in the informal sector only after having failed to find one in the formal sector.

In Satchi and Temple (2009) workers can be employed either in agriculture or in a man- 
ufacturing sector. Agriculture is taken as being perfectly competitive while in manufacturing there are formal firms subject to matching frictions, and informal self-employed workers who seek formal jobs. Although there is no labor market segmentation, informality is still viewed as a disadvantaged or residual sector in that paper.

Kolm and Larsen (2006) and Ulyssea (2009) assume, as we do, that unemployed workers seek both formal and informal jobs, and that both types of jobs are subject to matching frictions. Such assumptions on workers' search behavior seem consistent with the empirical evidence on the Brazilian labor market presented in the next section, where it is shown that there is a relatively large degree of mobility between formal and informal jobs. This also leads us to argue that job seekers probably accept both types of jobs and that the formal and informal labor markets are not segmented for the workers. Kolm and Larsen (2006) analyze the effects of higher punishment and audit rates on labor market performance, while Ulyssea (2009) focuses on endogenous differences in productivity between the two sectors. We abstract from those considerations to focus on differences in firm size across sectors, which render their relative degree of competitiveness endogenous.

Alternatively, Boeri and Garibaldi (2006) and Albrecht et al. (2009) are interested in explaining the sorting of workers across sectors, and they assume that workers differ in their productivity. We are aware of the empirical evidence suggesting differences in workers' skills and firms' productivity in formal and informal sectors, but the aim of our paper is not to explain these features.

A common assumption to all those previous models is that each firm is allowed to hire only one worker. We depart from this assumption and let firms hire as many workers as they desire. El Badaoui et al. (2010) develop, to our knowledge, the only alternative model in this literature in which firm size is also an endogenous variable. Based on Burdett and Mortensen (1998), they build a model with on-the-job search and wage posting (instead of wage bargaining) where firms' choice of wages determines their size. In our model, however, firms choose their size directly and wages are a result of a bargaining process between large firms and their workers. Additionally, firms size will ultimately have an effect on the number of firms in a sector, which, in turn, impacts firms' market power in the goods market.

The paper is organized as follows. Section 2 presents some stylized facts for the Brazilian economy. The theoretical model is described in Section 3. The equilibrium is derived in section 4 while section 5 provides some quantitative exercises. Section 6 concludes. Technical details are gathered in the appendix. 


\section{Stylized Facts}

We use data from the Monthly Employment Survey (Pesquisa Mensal de Emprego, or PME) conducted by the Brazilian Institute of Geography and Statistics (IBGE) for the greater metropolitan regions of Sao Paulo, Rio de Janeiro, Belo Horizonte, Porto Alegre, Salvador and Recife. PME collects information on employment and earnings, as well as on other observable characteristics such as the workers' years of schooling, age, gender, state of residence, sector of activity and occupation.

In Brazil, all workers formally employed in the private sector are required to have a working card ('carteira de trabalho'), thus, by observing whether the individual has a valid working card we are able to sort formal and informal workers. ${ }^{1}$ Among the self employed, it is also possible to distinguish those who pay social contributions from those who do not. We then define informal workers as those informally employed in the private sector and the self employed who do not pay social contribution. As shown in Figure 2, from 2003 to 2010 the share of the informal sector declined from around 40 to $35 \%$ in Brazil, while the unemployment rate also decreased from around 12 to $7 \%$.

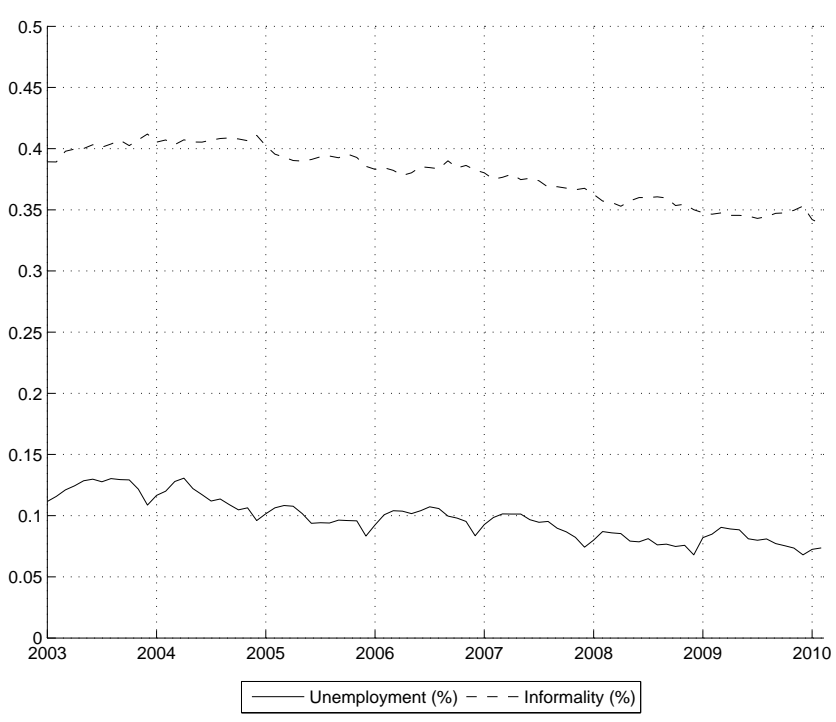

Figure 2: Informality and unemployment in Brazil

PME interviews the same individual at different moments in time for a period of 16 months. For each individual, four interviews are conducted over the first four months, then there is an

\footnotetext{
${ }^{1}$ Notice that we also need the information of whether the individual works in the public sector, since public servants do not hold a working card as well. This question was included in the PME questionnaire from 2002 on. We then choose to use data starting in 2002. For data prior to 2002 it was not possible to sort informal workers from those working in the public sector.
} 
interval of eight months, and once again the same individual is interviewed for four consecutive months. Thus the information is gathered in months $t, t+1, t+2, t+3, t+12, t+13, t+14$ and $t+15$. We use the fourth $(t+3)$ and eighth $(t+15)$ interviews of each individual to compute the transition frequencies across employment states. Table 1 below presents the transitions across unemployment, formality and informality, where each line displays the state of origin and the column the destination state. The table depicts some interesting patterns. An unemployed worker has virtually equal probability of being in either one of the three states one year later. Formal workers have a probability of $87.4 \%$ of remaining formal, while only $71.7 \%$ of informal workers remain informal after one year. Finally, informal workers become formal with a probability of $23.1 \%$, whereas the reverse is true with a frequency of only $9.3 \%$.

\begin{tabular}{|c|c|c|c|}
\hline State $\mathbf{T} \backslash$ State $\mathbf{T}+\mathbf{1}$ & Unemployed & $\begin{array}{l}\text { Employed: } \\
\text { Registered }\end{array}$ & $\begin{array}{l}\text { Employed: } \\
\text { Unregistered }\end{array}$ \\
\hline Unemployed & $35,8 \%$ & $32,1 \%$ & $32,1 \%$ \\
\hline Employed: Registered & $3,4 \%$ & $87,4 \%$ & $9,3 \%$ \\
\hline Employed: Unregistered & $5,3 \%$ & $23,1 \%$ & $71,7 \%$ \\
\hline Total & $6,6 \%$ & $62,2 \%$ & $31,2 \%$ \\
\hline Total Observations (Different Individuals) & \multicolumn{3}{|c|}{246574} \\
\hline Average Observations per Month & \multicolumn{3}{|c|}{3378} \\
\hline Overall Period & \multicolumn{3}{|c|}{ Jan 2003-Feb 2010} \\
\hline Estimation Sample & \multicolumn{3}{|c|}{ Jan 2004-Feb 2010} \\
\hline Source & & \multicolumn{2}{|c|}{ Monthly Labor Survey (PME) - IBGE } \\
\hline
\end{tabular}

Table 1: Transition probabilities

We have also computed the same transition matrix using two alternative subsamples. ${ }^{2}$ In first one we restrict the sample to workers 23 and 65 years old, which corresponds to 155,002 observations. In the second subsample we consider only low-skill workers (those with lower than high-school education), which amounts to 124,569 observations. In all cases, we get broadly the same picture, with marginal differences. In particular, there are more marked differences in the probabilities for an unemployed to find a formal or an informal job using those subsamples. In the first subsample, among the unemployed at time $t, 34.5 \%$ stay unemployed, $31.1 \%$ find a job in the formal sector, while $34.4 \%$ become an informal worker at $t+1$. In the second subsample, the same percentages are $34.9 \%, 29.4$ and $35.7 \%$ respectively.

As shown in Figure 3, formal sector wages are 45 to $55 \%$ higher than wages in the informal sector. We know, however, that formal and informal sector workers differ in a number of

\footnotetext{
${ }^{2}$ The results are available upon request.
} 
characteristics that affect wages. We then estimate the wage premium in the formal sector after controlling for observable individual characteristics available in the data. ${ }^{3}$ Controlled wage gap is indeed much smaller than the observed one but it is still considerable, ranging from 23 to $30 \%$, as shown in Figure 3.

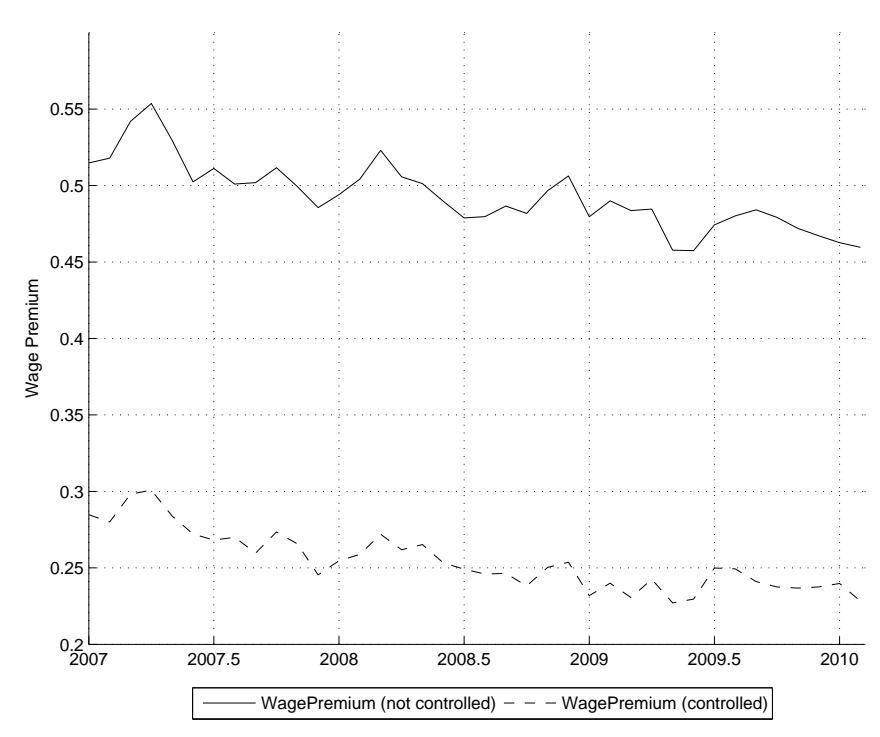

Figure 3: Wage Premium

With respect to firm size, while it is not possible to know the exact number of employees in a firm, we are able to divide firm size into three categories: the first one corresponds to firms with 2 to 5 employees, the second one with 6 to 10 employees, and the third with 11 employees or more. We create a size index by assigning a number from 1 to 3 to each of these categories. Figure 4 presents the averages of this size index for the informal and formal sectors. Formal sector firms are clearly larger than informal ones.

\section{The model}

We consider an economy with imperfect competition in the goods market and matching frictions in the labor market, populated by a continuum of risk neutral workers whose measure is normalized to unity. There are two sectors, formal $(F)$ and informal $(I)$, each producing one of the two consumption goods available in the economy.

\footnotetext{
${ }^{3}$ We run Mincer regressions in cross section for each month, where wages are explained by a dummy for informal workers, a dummy for each city, and the following worker's characteristics: age, age square, education, education square, and position in the household.
} 


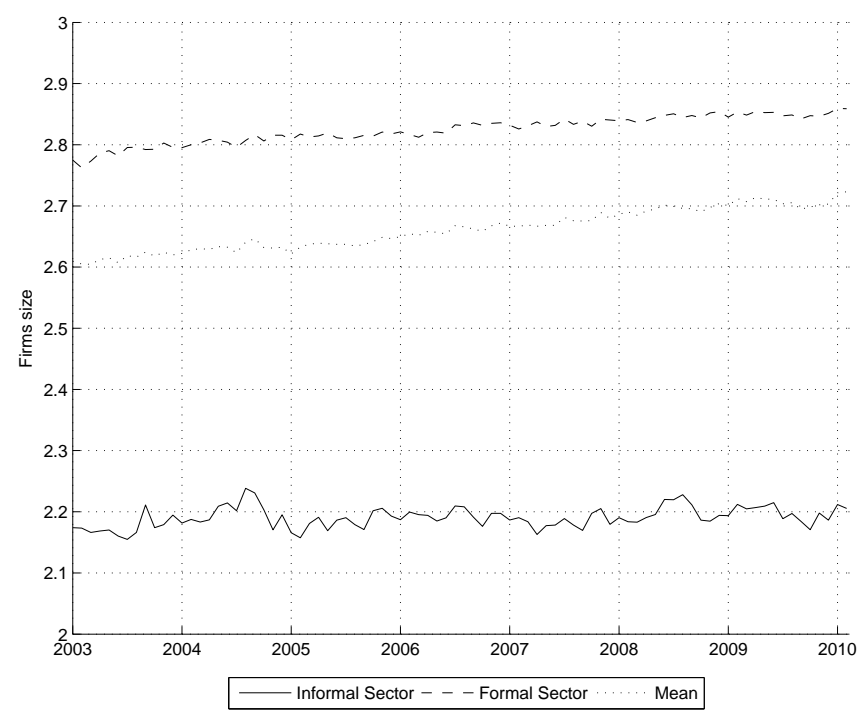

Figure 4: Firm size in formal and informal sectors

\subsection{The goods market}

Households derive utility from consuming goods from both formal and informal sectors, and their preferences are represented by the following utility function:

$$
U=\left[\alpha_{F}^{\frac{1}{\sigma}} C_{F}^{\frac{\sigma-1}{\sigma}}+\alpha_{I}^{\frac{1}{\sigma}} C_{I}^{\frac{\sigma-1}{\sigma}}\right]^{\frac{\sigma}{\sigma-1}}
$$

where $C_{F}$ and $C_{I}$ denote a household's consumption of the good produced in the formal and in the informal sectors, respectively, while $\sigma$ stands for the elasticity of substitution between the two goods. Assuming, for the sake of simplicity, that $\alpha_{F}=\alpha_{I} \equiv \alpha$, the optimal consumption pattern of a household $n$ with real income $Y_{n}$ is given by:

$$
C_{j n}=\alpha Y_{n}\left(\frac{p_{j}}{P}\right)^{-\sigma}, \text { for } j \in\{F, I\}
$$

where $p_{j}$ is the price index of sector $j$ good, $P$ is the composite price index, $P=\left(\alpha \sum_{j=I, F} p_{j}^{1-\sigma}\right)^{1 /(1-\sigma)}$, which we normalize to one without loss of generality. There is a continuum of identical consumers in the interval $[0,1]$, hence aggregate consumption is:

$$
C_{j}=\alpha Y\left(\frac{p_{j}}{P}\right)^{-\sigma}
$$

where $Y \equiv \int_{0}^{1} Y_{n} d n$ denotes aggregate income.

Firms in each sector are identical. In a symmetric equilibrium, they all produce an equal share of the total demand for the sector, hence firms may be labeled only by the industry $j$ they belong to. We then have that $C_{j}=N_{j} y_{j}$, where $y_{j}$ denotes the production of a firm and $N_{j}$ the 
number or firms in sector $j . N_{j}$ is fixed in the short run, while in the long run it responds to changes in market profitability and is determined by a free entry condition.

Using equation (2) and the normalization of the aggregate price index, we may write the inverse demand function as:

$$
p_{j}=\left(\frac{N_{j} y_{j}}{\alpha Y}\right)^{-\frac{1}{\sigma}} .
$$

In this way, as a result of Cournot competition among firms, the elasticity of demand faced by a firm in sector $j, \sigma_{j}$, is positively related to the number of firms operating in that sector as follows:

$$
\sigma_{j} \equiv \sigma_{j}\left(N_{j}\right)=\sigma N_{j}
$$

Thus, in this simple framework, we have that the number of firms, $N_{j}$, determines the level of competition for a firm in sector $j$. Several alternative ways to model imperfect competition in the goods market can be found in the literature, e.g. Blanchard and Giavazzi (2003), Delacroix (2006), Ebell and Haefke (2009), or Felbermayr and Prat (2010). Our main results would not change substantially when using alternative specifications.

Labor is the only input in production. Recent research on informality has highlighted the fact that informal firms are less productive than formal ones (see, for instance, Taymaz, 2009). We allow for productivity differences across sectors by defining production function as:

$$
y_{j}=A_{j} h_{j}
$$

where $A_{j}$ stands for a (sector-specific) productivity parameter and $h_{j}$ is the firm's size, that is, the number of workers employed. The size of firms will be endogenously determined in the model. We will see that, in equilibrium, firms in the informal sector are smaller, which is in accordance with the stylized fact described in section 2 and previous findings in the literature (see Rauch, 1991 or Tybout, 2000).

Combining demand function in equation (3) and the production function in (5), goods market is in equilibrium when:

$$
N_{j} A_{j} h_{j}=p_{j}^{-\sigma} \alpha Y
$$

\subsection{The labor market}

Empirical evidence indicates that informal workers have on average lower educational attainment levels (see, among others, Gong and Van Soest, 2002, Gong et al, 2004, and Maloney, 2004). Since informality would therefore be more a concern for low than for high skill workers, we 
choose to focus on identical workers ${ }^{4}$ searching for a job in the formal and in the informal sector simultaneously when unemployed.

Furthermore, we assume that both formal and informal sectors are subject to matching frictions in the labor market and that they share the same pool of unemployed workers. These two assumptions depart from other recent works that incorporate search-matching frictions to study informality, which assume a segmented labor market and takes the informal sector as a residual perfectly competitive sector.

In each sector, vacant jobs and unemployed workers are brought together in pairs by a matching function $M_{j}$. It maps the number of matches in sector $j, M_{j}$, to the total number of job seekers and vacancies in that sector:

$$
M_{j} \equiv M_{j}\left(u, v_{j}\right)
$$

where $u$ and $v_{j}$ correspond respectively to the mass of job seekers ${ }^{5}$, which is the unemployment rate in the economy, and to the mass of vacancies in the sector. The function $M_{j}$ features standard properties: it is twice continuously differentiable, increasing and concave in both of its arguments, it is linearly homogeneous, satisfies the Inada conditions and the boundary conditions $M_{j}\left(0, v_{j}\right)=M_{j}(u, 0)=0$ for $u, v_{j} \geq 0$.

We allow the matching function to be different across sectors to be able to capture their particularities. For instance, firms may rely on different methods to recruit their workers in the two sectors, so that the efficiency of the two matching processes may differ somewhat. It is also often argued that, compared to the formal sector, the informal sector is closer to a competitive market where it takes less time to match. In such a case, the matching process would be more efficient in the informal sector, resulting in more matches for the same level of inputs in the matching function.

On average, a firm contacts a worker at rate $M_{j} / v_{j}$ while a job seeker meets a sector $j$ firm at rate $M_{j} / u$. Let $\theta_{j} \equiv v_{j} / u$ be the labor market tightness. Linear homogeneity of the matching function allows us to write those contact rates as $M_{j} / v_{j} \equiv m_{j}\left(\theta_{j}\right)$, with $m_{j}^{\prime}\left(\theta_{j}\right)<0$, and $M_{j} / u=\theta_{j} m_{j}\left(\theta_{j}\right)$, which is an increasing function of $\theta_{j}$. Thus vacancies are filled at rate $m_{j}\left(\theta_{j}\right)$ in sector $j$ while workers exit unemployment at rate $\sum_{j=F, I} \theta_{j} m_{j}\left(\theta_{j}\right)$.

A few remarks are in order. First, differences in job finding rates between the formal and the informal sector can easily be captured with two matching functions having different scale

\footnotetext{
${ }^{4}$ This is of course a simplification compared to the papers studying the sorting mechanism between the two sectors (e.g. Boeri and Garibaldi, 2006, Albrecht et al., 2009), but our focus is not on explaining sorting patterns across sectors.

${ }^{5}$ We assume job seekers are 'truly' unemployed. Alternatively, we could assume that they are in fact selfemployed, and that the self-employed search for jobs.
} 
parameters. For instance, in the Cobb-Douglas case, $M_{F}=\kappa_{F} u^{\eta} v_{F}^{1-\eta}$ while $M_{I}=\kappa_{I} u^{\eta} v_{I}^{1-\eta}$, with $\kappa_{I} \geq \kappa_{F}$. Second, the assumption of search frictions in both sectors encompasses the particular case of perfect competition in the informal labor market considered in several papers. That would correspond to the limit case where $\kappa_{I} \rightarrow \infty$ in our framework, i.e. in a fully competitive labor market, where it takes no time to locate a job offer or to fill a vacancy. Finally, if it took no time to locate a formal job $\left(\theta_{F} m_{F}\left(\theta_{F}\right) \rightarrow \infty\right)$, all workers would be employed in the formal sector. Thus, matching frictions are an important reason for the existence of an informal sector, and the underlying assumption for the existence of the two sectors is that the formal sector is 'sufficiently' frictional.

Matches are dissolved at rate $d_{j}$, due either to an exogenous separation rate $s_{j}$ between firms and workers or to the exit of firms from the market, which occurs with probability $\delta_{j}$. Hence, the sector-specific destruction rate is:

$$
d_{j}=\delta_{j}+s_{j}\left(1-\delta_{j}\right)
$$

Workers can be either employed or unemployed so that:

$$
L_{F}+L_{I}=1-u
$$

where $L_{j}=N_{j} h_{j}$ denotes employment in sector $j$, and $u$ stands for unemployment. In steadystate equilibrium, the mass of unemployed workers that find a job in a sector has to equal the mass of workers that loose a job in that sector, that is:

$$
d_{j} L_{j}=\theta_{j} m_{j}\left(\theta_{j}\right) u
$$

Equation (10) states that when a fraction $d_{j}$ of the jobs in sector $j$ are destroyed, they are compensated by an inflow $\theta_{j} m\left(\theta_{j}\right) u$ of job seekers who are recruited in sector $j$.

\subsection{Firms' decisions}

Following a growing body of the literature, we depart from the basic matching model by assuming firms can hire more than one worker. This implies that firm size becomes an endogenous variable which responds to changes in firm's expected profits. This feature of the model allows us to analyze the determinants of the relative size of firms in the two sectors. In particular, firm size depends on the elasticity of substitution $\sigma_{j}$, as we will show below, due to the assumption of imperfect competition in the goods market.

Firms choose the number of vacancies and its size so as to maximize expected profits, which can be written as:

$$
V_{j}\left(h_{j}\right)=\max _{v_{j}, h_{j}^{\prime}} \frac{1}{1+r}\left[p_{j}\left(y_{j}\right) y_{j}\left(h_{j}\right)-w_{j}\left(h_{j}\right) h_{j}\left(1+\tau_{j}\right)-\gamma_{j} v_{j}+\left(1-\delta_{j}\right) V_{j}\left(h_{j}^{\prime}\right)\right],
$$


where $r$ is the interest rate, $\gamma_{j}$ is the cost of a vacancy, $\tau_{j}$ represent taxes on labor costs, and $w_{j}\left(h_{j}\right)$ is the wage function resulting from a bargaining process, which will be derived in the next section. $h_{j}$ and $h_{j}^{\prime}$ represent the number of workers in current and next periods, respectively. The inverse demand function $p_{j}\left(y_{j}\right)$ is given by equation (3), while the production function $y_{j}\left(h_{j}\right)$ is in equation (5). Notice that, in this setting, firms do not take prices as given in the final goods market, as shown by the inverse demand function, and enjoy some bargaining power in the labor market, given by the wage function.

The number of workers next period, $h_{j}^{\prime}$, is determined by the following transition function:

$$
h_{j}^{\prime}=m_{j}\left(\theta_{j}\right) v_{j}+\left(1-s_{j}\right) h_{j},
$$

that is, next period's employment is equal to the number of matches for the vacancies posted plus the number of current workers that remain employed. Thus, firms advertise as many vacancies as necessary in order to hire, in expected value, the desired number of workers next period, taking into account the cost of a vacancy $\gamma_{j}$ and the constraints on labor market flows given by the transition function (12).

The optimal number of vacancies posted is such that the marginal contribution of a worker to the firm's expected profit is equal to the expected search cost, that is:

$$
\left(1-\delta_{j}\right) \frac{\partial V_{j}\left(h_{j}^{\prime}\right)}{\partial h_{j}^{\prime}}=\frac{\gamma_{j}}{m_{j}\left(\theta_{j}\right)}
$$

From the profit function (11), the marginal contribution of a worker to the firm's profit, denoted the envelope condition, can be written as:

$$
\frac{\partial V_{j}\left(h_{j}\right)}{\partial h_{j}}=\frac{1}{1+r}\left[\frac{\sigma_{j}-1}{\sigma_{j}} p_{j} A_{j}-\left(w_{j}\left(h_{j}\right)+\frac{\partial w_{j}\left(h_{j}\right)}{\partial h_{j}} h_{j}\right)\left(1+\tau_{j}\right)+\left(1-\delta_{j}\right)\left(1-s_{j}\right) \frac{\partial V_{j}\left(h_{j}^{\prime}\right)}{\partial h_{j}^{\prime}}\right],
$$

where we have used the fact that $\frac{\partial p_{j}\left(y_{j}\right)}{\partial y_{j}} \frac{\partial y_{j}}{\partial h_{j}} y_{j}+p_{j} \frac{\partial y_{j}}{\partial h_{j}}=\frac{\sigma_{j}-1}{\sigma_{j}} p_{j} A_{j}$ and that $\frac{\partial h_{j}^{\prime}}{\partial h_{j}}=1-s_{j}$. The term $\frac{\sigma_{j}-1}{\sigma_{j}} p_{j} A_{j}$ corresponds to marginal revenue to which the marginal costs $\left(w_{j}\left(h_{j}\right)+\frac{\partial w_{j}\left(h_{j}\right)}{\partial h_{j}} h_{j}\right) \times$ $\left(1+\tau_{j}\right)$ of expanding the labor force to $h_{j}$ should be subtracted. Marginal costs differs from wage since firms take into account the effect of an additional worker on the wages of previously employed workers.

In steady state firms' size is constant, that is, $h_{j}=h_{j}^{\prime}$. Hence, from equation (13) we have that:

$$
\frac{\partial V_{j}\left(h_{j}\right)}{\partial h_{j}}=\frac{\partial V_{j}\left(h_{j}^{\prime}\right)}{\partial h_{j}^{\prime}}=\frac{\gamma_{j}}{m_{j}\left(\theta_{j}\right)\left(1-\delta_{j}\right)}
$$


Substituting the envelope condition (14) into the optimal vacancies condition (13), and using the steady state condition (15), we get that:

$$
p_{j}\left(h_{j}\right)=\frac{1}{A_{j}}\left(\frac{\sigma_{j}}{\sigma_{j}-1}\right)\left[\left(w_{j}\left(h_{j}\right)+\frac{\partial w_{j}\left(h_{j}\right)}{\partial h_{j}} h_{j}\right)\left(1+\tau_{j}\right)+\frac{\gamma_{j}\left(r+d_{j}\right)}{m_{j}\left(\theta_{j}\right)\left(1-\delta_{j}\right)}\right]
$$

Equation (16) defines firms' pricing behavior in steady state, and can be interpreted as a mark-up equation over total labor costs, inclusive of wages and search costs. Firms enjoy some market power on the goods market, but also on the labor market, due to the existence of search frictions. In the absence of frictions, price $p_{j}$ would simply be equal to $\frac{1}{A_{j}}\left(\frac{\sigma_{j}}{\sigma_{j}-1}\right) w_{j}$. Here, though, the marginal cost of labor also takes into account the existence of recruitment costs and the impact of an additional worker on the wages of the infra-marginal workers, $\frac{\partial w_{j}\left(h_{j}\right)}{\partial h_{j}} h_{j}$. The latter term is negative, as shown in next section. This means that employers exploit decreasing marginal returns in order to reduce the wages of each infra marginal worker. For this reason the term is usually denoted in the literature as the overemployment or overhiring effect. Alternatively, equation (16) can be interpreted as a labor demand equation which relates the firms' optimal employment and wages choices.

Notice that using the steady-state condition that $\frac{\partial V_{j}\left(h_{j}\right)}{\partial h_{j}}=\frac{\partial V_{j}\left(h_{j}^{\prime}\right)}{\partial h_{j}^{\prime}}$, the envelope condition (14) can alternatively be written as:

$$
\frac{\partial V_{j}\left(h_{j}\right)}{\partial h_{j}}=\frac{1}{r+d_{j}}\left[A_{j} \frac{\sigma_{j}-1}{\sigma_{j}} p_{j}-\left(w_{j}\left(h_{j}\right)+\frac{\partial w_{j}\left(h_{j}\right)}{\partial h_{j}} h_{j}\right)\left(1+\tau_{j}\right)\right]
$$

which will be useful for the derivation of the wage function.

\subsection{Wage Bargaining}

Let $E_{j}$ and $U$ denote respectively the asset values of a worker employed in sector $j(j \in\{F, I\})$ or searching for a job. An unemployed worker enjoys a flow utility $z$, which may correspond to e.g. a combination of home-production and/or flow utility from leisure enjoyed while unemployed. He has an utility gain of $\left(E_{j}-U\right)$ when he finds a job in sector $j$, which occurs with probability $\theta_{j} m\left(\theta_{j}\right)$. Thus, in steady state we have that:

$$
r U=z+\theta_{F} m\left(\theta_{F}\right)\left(E_{F}-U\right)+\theta_{I} m\left(\theta_{I}\right)\left(E_{I}-U\right)
$$

A worker employed in sector $j$, on his turn, receives a wage $w_{j}$ and incurs an utility loss of $U-E_{j}$ when the job is destroyed, which occurs at rate $d_{j}$. We then have that:

$$
r E_{j}=w_{j}+d_{j}\left(U-E_{j}\right)
$$


which implies that the benefit of holding a job in sector $j$ over continued search is equal to the difference between the wage $w_{j}$ and the worker's reservation product $r U$, that is:

$$
E_{j}-U=\frac{w_{j}-r U}{r+d_{j}}
$$

Workers are not paid their full marginal product as in the standard neoclassical framework due to a combination of costly search and matching frictions which give rise to rent sharing. Most of the papers which study informality incorporating search frictions assume that wages result from Nash bargaining between one worker and one firm in the sector that experiences search frictions. We assume alternatively that bargaining takes place between a firm and its multiple workers, each worker being treated as the marginal worker. This is a good representation of reality when firms cannot commit to long-term contracts and may renegotiate wages with each worker at any time (Stole and Zwiebel, 1996). This seems an adequate framework to represent a case like the Brazilian one, where job turnover is extremely high (see Gonzaga, 2003).

Furthermore, this interesting alternative assumption has not been implemented yet in the literature studying the composition of employment in terms of formal vs informal jobs. We follow a growing body of the literature that has applied this assumption in studies not related to informality. See, among others, Bertola and Caballero (1994), Smith (1999), Cahuc and Wasmer (2001), Delacroix (2006), Cahuc, Marque and Wasmer (2008), Ebell and Haefke (2009) Mortensen, (2009), Felbermayr and Prat (2010).

As it will become clear later, bargaining with multiple workers introduces some important differences compared to the standard one-worker-per-firm framework, as under the neoclassical framework where wages equal marginal product. In particular, this gives rise to an overhiring externality according to which firms hire workers above the point where the marginal revenue from hiring the marginal worker equals marginal cost, since by doing so the wage of all inframarginal workers is reduced. ${ }^{6}$

The bargain between firms and the marginal worker yields:

$$
\left(1-\beta_{j}\right)\left(E_{j}-U\right)=\frac{\beta_{j}}{1+\tau_{j}} \frac{\partial V_{j}\left(h_{j}\right)}{\partial h_{j}} .
$$

where $\beta_{j} \in[0,1]$ can be interpreted as workers' bargaining power. Note that the bargaining power variable could be interpreted here as resulting from institutions that impede the functioning of the labor market and allow workers to extract rents, as in Blanchard and Giavazzi (2003). Using equations (17), (20) and (21), after some algebra it is possible to show that the

\footnotetext{
${ }^{6}$ Our framework is fairly general. It is always possible to compare the situation where overhiring is ruled out to the case where it takes place. It is also possible to allow for overhiring in one sector only. This exercise is deferred to section 5 .
} 
wage $w_{j}$ is a solution to the following differential equation: ${ }^{7}$

$$
w_{j}\left(h_{j}\right)=\left(1-\beta_{j}\right) r U+\beta_{j}\left[\frac{A_{j}}{1+\tau_{j}} \frac{\sigma_{j}-1}{\sigma_{j}} p_{j}-\frac{\partial w_{j}\left(h_{j}\right)}{\partial h_{j}} h_{j}\right],
$$

which has the following solution:

$$
w_{j}\left(h_{j}\right)=\left(1-\beta_{j}\right) r U+\beta_{j} \frac{\sigma_{j}-1}{\sigma_{j}-\beta_{j}} \frac{A_{j} p_{j}\left(h_{j}\right)}{1+\tau_{j}} .
$$

Equation (23) can be interpreted as the wage curve, which defines the wage as a weighted average of workers' reservation value $r U$ and of firm's marginal revenue, captured by the term $\frac{\sigma_{j}-1}{\sigma_{j}-\beta_{j}} \frac{p_{j}\left(h_{j}\right) A_{j}}{1+\tau_{j}}$

The relation between wages and employment is clear when one evaluates $\frac{\partial w_{j}\left(h_{j}\right)}{\partial h_{j}} h_{j}$. Combining equations (22) and (23) we get:

$$
\frac{\partial w_{j}\left(h_{j}\right)}{\partial h_{j}} h_{j}=-\underbrace{\frac{\sigma_{j}-\beta_{j}}{\sigma_{j}}}_{\text {overhiring }(<1)} \quad \underbrace{\frac{\sigma_{j}}{\sigma_{j}-1}}_{\text {market power }(>1)} \quad \frac{\beta_{j} A_{j} p_{j}\left(h_{j}\right)}{\sigma_{j}\left(1+\tau_{j}\right)}<0 .
$$

It is clear from equation (24) that wage depends on a term combining overhiring and market power effects. The equation also implies that the bargained wage is a decreasing function of employment. This is due to the fact that the firm's marginal revenue decreases with the number of workers, since the increased production from hiring an extra worker tends to reduce the price $p_{j}$. This effect is taken into account by the firms enjoying some market power. Given that each worker is treated as the marginal worker, hiring one more worker reduces the wage by $\left|\frac{\partial w_{j}\left(h_{j}\right)}{\partial h_{j}}\right|$. This leads to the so-called overhiring externality.

Notice that the overhiring effect differs across sectors, since they have different market and bargaining powers. From equation (24), the overhiring externality increases with workers' bargaining power $\beta_{j}$ and decreases with competition $\sigma_{j}$. It vanishes when $\beta_{j} \rightarrow 0$ or $\sigma_{j} \rightarrow \infty$. In such limit cases, workers are paid a constant wage: they get their reservation wage in the first case, while the marginal product of a worker is constant under full competition in the second. Such limit cases are more likely to apply to the informal sector, since workers' bargaining power is smaller in the informal sector and competition is more intense than in the formal sector.

We substitute the wage equation (23) and its derivative (24) into the mark-up equation (16) to get:

$$
p_{j}=\frac{1}{A_{j}} \frac{\sigma_{j}-\beta_{j}}{\sigma_{j}-1}\left[r U\left(1+\tau_{j}\right)+\frac{1}{1-\beta_{j}} \frac{\gamma_{j}\left(r+d_{j}\right)}{m_{j}\left(\theta_{j}\right)\left(1-\delta_{j}\right)}\right],
$$

which establishes the optimal price set by the firm as a function exclusively of variables exogenous to the firm's decision. Notice that the factor $\frac{\sigma_{j}-\beta_{j}}{\sigma_{j}-1}$ can again be decomposed as $\frac{\sigma_{j}-\beta_{j}}{\sigma_{j}} \frac{\sigma_{j}}{\sigma_{j}-1}$. It

\footnotetext{
${ }^{7}$ See appendix for the derivation of equations (22) and (23).
} 
is then straightforward to establish that the price is decreasing with the overhiring externality and it is increasing with market power, at given tightness.

Finally, we substitute price from equation (25) into the wage equation (23) to derive wages also as a function of variables the firm takes as given when making decisions:

$$
w_{j}=r U+\frac{\beta_{j}}{1-\beta_{j}} \frac{\gamma_{j}\left(r+d_{j}\right)}{m_{j}\left(\theta_{j}\right)\left(1-\delta_{j}\right)\left(1+\tau_{j}\right)}
$$

Combining equations (16) and (24) we get the equation that determines the optimal employment choice:

$$
\left[w_{j}\left(h_{j}\right)\left(1+\tau_{j}\right)+\frac{\gamma_{j}\left(r+d_{j}\right)}{m_{j}\left(\theta_{j}\right)\left(1-\delta_{j}\right)}\right] \frac{\sigma_{j}-\beta_{j}}{\sigma_{j}}=A_{j} p_{j}\left(h_{j}\right) \frac{\sigma_{j}-1}{\sigma_{j}}
$$

According to equation (27), firms set employment, and therefore wages, so as to equalize marginal costs to marginal revenue. Marginal revenue, on the right hand side, includes a factor $\frac{\sigma_{j}-1}{\sigma_{j}}<1$, due to their market power in the goods market. Marginal costs, on the left hand side of the equation, consist of wages, taxes on labor and expected search costs. It is weighted by an overhiring factor $\frac{\sigma_{j}-\beta_{j}}{\sigma_{j}}<1$, which establishes that they set $h_{j}$ above the efficient level where benefit from hiring the marginal worker equals his cost. Firms are willing to do so because they are aware that hiring more workers tends to depress wages paid for their entire workforce. In our two-sector setting, overhiring should be less important in the sector where workers' bargaining power $\beta_{j}$ is smaller or where the elasticity $\sigma_{j}$ is larger. Typically, that should be the case in informal sectors where there is a larger number of firms and where workers have lower bargaining power (see Camargo, 2003). ${ }^{8}$

\section{Equilibrium}

\subsection{Equilibrium in the short-run}

We are now ready to determine the short-run equilibrium where the number of firms in each sector is constant. Given our previous assumptions, having a fixed number of competitors $N_{j}$ is equivalent to fixing the elasticity $\sigma_{j}$ faced by each firm in industry $j$. Hence a short-run equilibrium is defined for a given value of $N_{j}$ for each industry, while prices $p_{j}$, wages $w_{j}$, firm size $h_{j}$ and sectoral employment $L_{j}=N_{j} h_{j}$, aggregate unemployment $u=1-\sum_{j=I, F} L_{j}$, tightness $\theta_{j}$ and workers' reservation value are endogenously determined. In the simulations of the model we do comparative statics analysis to investigate the impact of some of the parameters.

\footnotetext{
${ }^{8}$ Notice that the intuition provided here takes workers' outside options are fixed. Section 5 studies the impact of such a wage bargaining externality when workers' outside options are endogenous. It is then shown that overhiring in the formal sector may translate into underhiring in the informal sector. In any case, there are reasons to think that the so-called overhiring externality implies a smaller relative size of the informal sector.
} 
In particular, we highlight the impact of fiercer competition on all variables in the short run by investigating the impact of changes in the degree of competition $\sigma_{j}=\sigma N_{j}$, captured by a change in $N_{j}$.

Equations (25) and (26) establish optimal prices and wages as a function of labor market tightness and workers' reservation value. Using the wage bargaining equation (21) and the expression that determines the optimal number of vacancies (13), workers' reservation value from equation (18) can be rewritten as a function of the labor market tightness, as in:

$$
r U=z+\sum_{j=F, I} \frac{1}{1+\tau_{j}} \frac{\beta_{j}}{1-\beta_{j}} \frac{\gamma_{j} \theta_{j}}{1-\delta_{j}} .
$$

With equation (28), the equations for prices (25) and for wages (26) may also be written as functions of sectoral tightness, as follows: ${ }^{9}$

$$
\begin{gathered}
p_{j}\left(\theta_{j}, \theta_{k}\right)=\frac{\sigma_{j}-\beta_{j}}{\sigma_{j}-1} \frac{1}{A_{j}}\left[\left(1+\tau_{j}\right) z+\frac{1+\tau_{j}}{1+\tau_{k}} \frac{\beta_{k}}{1-\beta_{k}} \frac{\gamma_{k} \theta_{k}}{1-\delta_{k}}+\frac{r+d_{j}+\beta_{j} \theta_{j} m_{j}\left(\theta_{j}\right)}{\left(1-\beta_{j}\right)\left(1-\delta_{j}\right)} \frac{\gamma_{j}}{m_{j}\left(\theta_{j}\right)}\right], \\
\text { and } w_{j}\left(\theta_{j}, \theta_{k}\right)=z+\frac{\beta_{j}}{1-\beta_{j}} \frac{\gamma_{j}\left(r+d_{j}+\theta_{j} m_{j}\left(\theta_{j}\right)\right)}{\left(1-x_{j}\right) m_{j}\left(\theta_{j}\right)\left(1+\tau_{j}\right)}+\frac{1}{1+\tau_{k}} \frac{\beta_{k}}{1-\beta_{k}} \frac{\gamma_{k} \theta_{k}}{1-\delta_{k}}
\end{gathered}
$$

for $j, k \in\{I ; F\}$ and $k \neq j$. It is worth noting that prices and wages in each sector $j$ also depend on the other sector's variables, including labor market tightness $\theta_{k}$. This is basically a consequence of our assumption that workers search employment in both sectors simultaneously, which implies that workers' reservation value depends on labor market conditions of both sectors as stated by equation (28), while wages and prices are themselves functions of this reservation value.

We now have to determine labor market tightness in the two sectors $\left(\theta_{F}^{*}, \theta_{I}^{*}\right)$. They are determined by the equilibrium conditions in the goods and in the labor markets as follows. First, using equation (6) we get the employment ratio between the informal and formal sectors that satisfy the goods market equilibrium. We denote it the product market equilibrium (PME) condition:

$$
\frac{L_{I}^{*}}{L_{F}^{*}}=\frac{A_{F}}{A_{I}}\left[\frac{p_{I}\left(\theta_{F}^{*}, \theta_{I}^{*}\right)}{p_{F}\left(\theta_{F}^{*}, \theta_{I}^{*}\right)}\right]^{-\sigma},
$$

which defines implicitly the intersectoral allocation of labor as a function of relative prices and relative productivity, an usual property.

Note that the ratio $L_{I}^{*} / L_{F}^{*}$ is a function of tightness $\theta_{F}^{*}$ and $\theta_{I}^{*}$ due to the (positive) dependence of prices $p_{F}$ and $p_{I}$ on these variables, as highlighted by equation (29). A rise in $\theta_{j}^{*}$, would imply a rise in wages (see equation (26)), translating into a higher price. The quantity

\footnotetext{
${ }^{9}$ With some abuse of notation, we now write prices and wage as functions of labor market tightness: $p_{j}\left(\theta_{j}, \theta_{k}\right)$ and $w_{j}\left(\theta_{j}, \theta_{k}\right)$.
} 
consumed thus decreases, resulting in lower employment in the sector. However, as given by PME condition (31), the relative labor allocation $L_{I}^{*} / L_{F}^{*}$ depends on relative (rather than absolute) prices. Since both prices depend positively on $\theta_{F}^{*}$ and $\theta_{I}^{*}$, the impact of a change in these variables on relative prices is ambiguous. It depends on which price is more sensitive to changes in labor market tightness, which is captured by a condition on price elasticities. ${ }^{10}$ The comparative statics properties of this relationship is ambiguous as well, since it depends on which price is impacted the most by a change in parameters in equation (31). ${ }^{11}$

Second, from equation (10) we derive the relative employment in the two sectors that is compatible with equilibrium in the labor market. We get then the labor market equilibrium (LME) condition:

$$
\frac{L_{I}^{*}}{L_{F}^{*}}=\frac{d_{F}}{d_{I}} \frac{\theta_{I}^{*} m_{I}\left(\theta_{I}^{*}\right)}{\theta_{F}^{*} m_{F}\left(\theta_{F}^{*}\right)} .
$$

which defines the intersectoral allocation of labor as a function of sectoral tightness, efficiency parameter of the matching processes and turnover rates. Hence, the LME condition imply that the informal sector is relatively larger when its own labor market tightness $\theta_{I}^{*}$ is higher and when the formal sector's tightness $\theta_{F}^{*}$ is lower. Moreover, the formal sector is larger also when its own destruction rate of jobs is lower and the informal sector's one is higher.

The intersectoral allocation of labor in equilibrium is determined when PME and LME relationships are satisfied simultaneously. Hence, by equalizing equations (31) and (32) and making use of the price equation (29), we determine the Intersectoral Allocation of Labor curve (IALC): ${ }^{12}$

$$
\frac{d_{F}}{d_{I}} \frac{\theta_{I}^{*} m_{I}\left(\theta_{I}^{*}\right)}{\theta_{F}^{*} m_{F}\left(\theta_{F}^{*}\right)}=\frac{A_{F}}{A_{I}}\left[\frac{p_{I}\left(\theta_{F}^{*}, \theta_{I}^{*}\right)}{p_{F}\left(\theta_{F}^{*}, \theta_{I}^{*}\right)}\right]^{-\sigma},
$$

which determines a first relationship between $\theta_{F}^{*}$ and $\theta_{I}^{*}$.

A second relationship between the two sectoral tightnesses is obtained using the price equation (29) and the definition of the aggregate price index:

$$
P^{*}=1=\alpha^{\frac{1}{1-\sigma}}\left[p_{I}\left(\theta_{I}^{*}, \theta_{F}^{*}\right)^{1-\sigma}+p_{F}\left(\theta_{I}^{*}, \theta_{F}^{*}\right)^{1-\sigma}\right]^{\frac{1}{1-\sigma}} .
$$

We get the Price Curve (PC):

$$
1-\alpha p_{I}\left(\theta_{I}^{*}, \theta_{F}^{*}\right)^{1-\sigma}=\alpha p_{F}\left(\theta_{I}^{*}, \theta_{F}^{*}\right)^{1-\sigma}
$$

\footnotetext{
${ }^{10}$ Differentiating equation (31) we get that the ratio $L_{I}^{*} / L_{F}^{*}$ increases with $\theta_{I}^{*}$ if and only if $\varepsilon_{p_{F} / \theta_{I}}>\varepsilon_{p_{I} / \theta_{I}}$. Similarly, the ratio $L_{I}^{*} / L_{F}^{*}$ decreases with $\theta_{F}^{*}$ if and only if $\varepsilon_{p_{F} / \theta_{F}}<\varepsilon_{p_{I} / \theta_{F}}$. Nevertheless, such restrictions may not always hold.

${ }^{11}$ We therefore study the comparative statics on the basis of numerical exercises, and we get monotonic responses of $\frac{L_{I}^{*}}{L_{F}^{*}}$ to changes in the parameters considered. See section 5 .

${ }^{12} \mathrm{As}$ mentioned above, the relationship is not necessarily monotonic. We however check in our simulations that this condition is satisfied.
} 
which defines a decreasing relationship between $\theta_{I}^{*}$ and $\theta_{F}^{*}$.

The IALC and PC relationships together determine the equilibrium levels of labor market tightness in the two sectors, $\theta_{F}^{*}$ and $\theta_{I}^{*}$, by means of a fixed point argument. The equilibrium is unique provided the IALC relationship evolves monotonically with respect to $\theta_{I}^{*}$ and $\theta_{F}^{*}$, as represented in Figure 5. The numerical simulation in the next section checks this monotonicity, and Figure 13 depicts the corresponding equilibrium.

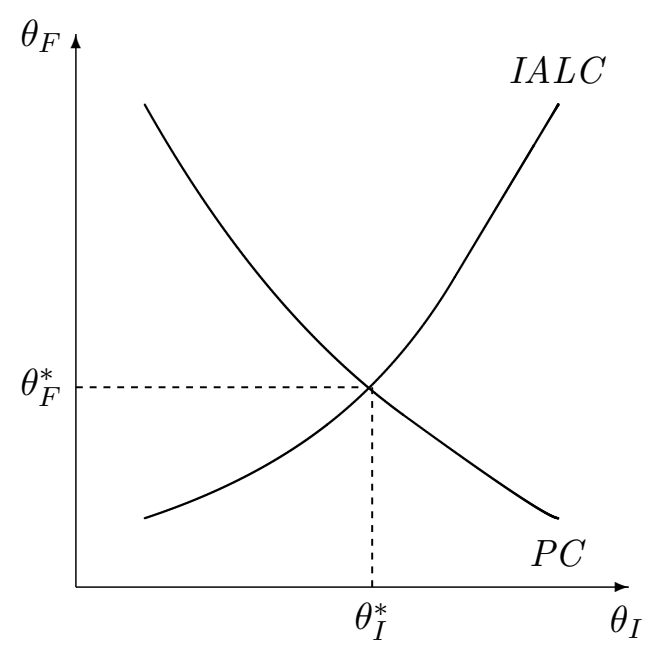

Figure 5: Unique Equilibrium

Once having determined equilibrium values for labor market tightness $\theta_{I}^{*}$ and $\theta_{F}^{*}$, all other variables of the model follow: prices $p_{j}^{*} \equiv p_{j}\left(\theta_{I}^{*}, \theta_{F}^{*}\right)$ and wages $w_{j}^{*} \equiv w_{j}\left(\theta_{I}^{*}, \theta_{F}^{*}\right)$ are determined as a function of tightness in equations (29) and (30). Workers' reservation product $r U^{*}$ is also a function of tightness as a result from (28). As for sectoral employment levels, the labor market equilibrium conditions (9) and (10) imply:

$$
\begin{gathered}
L_{j}^{*}=\left[1+\frac{d_{j}}{\theta_{j}^{*} m\left(\theta_{j}^{*}\right)}+\frac{d_{j}}{d_{k}} \frac{\theta_{k}^{*} m_{k}\left(\theta_{k}^{*}\right)}{\theta_{j}^{*} m_{j}\left(\theta_{j}^{*}\right)}\right]^{-1}, \text { for } j, k \in\{F, I\}, \text { and } k \neq j \\
u^{*}=1-L_{F}^{*}-L_{I}^{*},
\end{gathered}
$$

and, by definition, $v_{j}^{*}=\theta_{j}^{*} u^{*}$ while $h_{j}^{*}=L_{j}^{*} / N_{j}$, where $N_{j}$ can be treated as a parameter in the short run, and will be endogenized in the longer run.

From equation (34), employment in a sector is an increasing function of its own tightness and a decreasing function of the other sector's tightness. The intuition is the following. If, for instance, tightness $\theta_{j}^{*}$ increases in a sector, workers will find jobs in that sector more easily, thus increasing employment in that sector. Then, from (35), it turns out that unemployment decreases when employment increases in formal or informal sectors. 
Finally, in equilibrium total income equals total product, hence:

$$
Y^{*}=\sum_{j=I, F} A_{j} p_{j}\left(\theta_{j}^{*}, \theta_{k}^{*}\right) L_{j}\left(\theta_{j}^{*}, \theta_{k}^{*}\right)
$$

Formal and informal sectors are interdependent for basically two reasons : (i) in equilibrium, demand for goods and therefore sectors' relative size depend on relative prices, as it is clear from equation (31); (ii) workers search for jobs in both sectors, as established by equation (18). As a result, a change in sector-specific parameters affects both sectors, as will be shown in the next section through numerical exercises. ${ }^{13}$

\subsection{Long-run general equilibrium}

The next step is to determine the long run equilibrium in which the number of firms in each industry is endogenous. The timing of events is the following. At the beginning of a period firms decide whether enter the market. If they enter they pay an entry cost, $c_{j}$, on top of the cost of posting vacancies in a number sufficient to recruit the desired amount of workers. ${ }^{14}$ Business is then started and profits are received at the end of that period/beginning of the next period.

Entry costs entail direct administrative costs as well as indirect costs due to administrative delays. Several of the entry costs do not apply to the informal sector, such as, for instance, the official registration to comply with legislation. Although it would be fair to say that barriers to entry are essentially a problem in the formal sector, informal firms may still incur in entry costs since it may take some time and resources to set up a business in this sector. It is then reasonable to assume that $0 \leq c_{I}<c_{F}$.

In equilibrium, the free entry condition establishes that the costs of setting a business must equal its profits, as in:

$$
c_{j}+\frac{\gamma_{j} h_{j}^{*}}{m_{j}\left(\theta_{j}^{*}\right)}=\frac{1+r}{r+\delta_{j}} \pi_{j}^{*}, \text { for } j \in\{I, F\},
$$

where the second term in the left-hand side corresponds to the cost of posting vacancies to hire the desired amount of labor $h_{j}^{*}$, and $\pi_{j}^{*}$ stands for profits, which is given by:

$$
\begin{aligned}
\pi_{j}^{*} & =p_{j}^{*} A_{j} h_{j}^{*}-w_{j}^{*} h_{j}^{*}\left(1+\tau_{j}\right)-\gamma_{j} v_{j}^{*} \\
& =p_{j}^{*} A_{j} h_{j}^{*}-w_{j}^{*} h_{j}^{*}\left(1+\tau_{j}\right)-\gamma_{j} s_{j} h_{j}^{*} / m_{j}\left(\theta_{j}^{*}\right) .
\end{aligned}
$$

\footnotetext{
${ }^{13}$ The case with identical sectors is studied in the appendix. In that case, the IALC curve becomes the $45^{\circ}$ line, and only the $\mathrm{PC}$ curve with $\theta_{I}=\theta_{F}$ shifts as parameters change.

${ }^{14}$ Notice that, in our setup, firms jump to their steady state size when they enter the market. This is a consequence of our assumption of linearity of adjustment costs. See Bertola and Caballero (1994) for a model with convex costs. See also Acemoglu and Hawkins (2010) for an alternative framework where firms cannot hire a large number of workers in each period.
} 
In the previous section we have derived all short run variables as functions of labor market tightness $\theta_{I}^{*}$ and $\theta_{F}^{*}$, which are themselves parameterized by the number of firms operating in each sector, $N_{I}$ and $N_{F}$. Hence, in a long run equilibrium, all variables are defined as functions of $N_{I}$ and $N_{F}$ and equation (37) closes the model .

Firms' profit opportunities decline with the number of firms operating in the market $N_{j}^{*}$ since with more firms there is more competition and lower markups. Under free entry, a rise in the left hand side of the free entry condition (37), for instance, due to an increase in entry costs $c_{j}$ or in hiring costs $\frac{\gamma_{j} h_{j}^{*}}{m_{j}\left(\theta_{j}^{*}\right)}$ must be compensated by an equal rise of the right hand side of $(37)$, i.e. higher profits, which is obtained by a smaller equilibrium number of firms.

\section{$5 \quad$ Numerical simulations}

\subsection{Parametrization and calibration}

We choose parameters with two criteria in mind: (i) they have to be realistic and coherent with the values usually used in the literature, (ii) the values of endogenous variables stemming from the simulations have to be realistic and/or comparable with the values found in previous studies. We choose the Brazilian economy to guide our parametrization. Brazil is a large developing country with a sizable informal sector, with the advantage of having high quality micro data available, which has already been exploited in a number of empirical studies. Hence, we have both access to data and to other studies that have worked on them.

Our reference period is a month and we use 2003 as reference year. The discount rate $r$ is set to $0.6434 \%$ which correspond to an annual rate of $8 \%$ as in Heckman and Pagés (2003). All relevant variables and parameters are allowed to differ between the formal and the informal sectors. Informal sector firms are assumed to be less productive than formal ones, and their productivity is normalized to one. The productivity parameter in the formal sector is 2 , capturing a productivity differential of $100 \%$ between the two sectors, as used by other studies (see, for instance, Ulyssea, 2009). In terms of our notation, we have then that $A_{F}=2$ and $A_{I}=1$.

In a recent study, Bartelsman, Haltiwanger, and Scarpetta (2009) estimate that the annual exit rate for Brazilian firm ranges between $5 \%$ to 10\%, and they indicate that exit rate is higher among smaller firms. Since firms are on average smaller in the informal sector than in the formal one, we use the lower bound of the interval to define firms' exit rate in the formal sector and, conversely, the upper bound to define firms' exit rate in the informal sector. It follows that the monthly values for the two parameters are set to $\delta_{F}=0.0041$ and $\delta_{I}=0.0080$ which is consistent with the intuition that on average firms' turnover is higher in the informal sector, i.e. 
Table 2: Baseline Parameters

\begin{tabular}{|c|c|c|c|c|}
\hline \multirow[t]{2}{*}{ Parameter } & \multicolumn{2}{|c|}{ Sector } & \multirow[t]{2}{*}{ Formal/informal } & \multirow[t]{2}{*}{ Description } \\
\hline & Formal & Informal & & \\
\hline$A_{j}$ & 2 & 1 & 2 & Productivity \\
\hline$\delta_{j}$ & $0.41 \%$ & $0.80 \%$ & 0.51 & Firms exit rate \\
\hline$d_{j}$ & $1.02 \%$ & $2.21 \%$ & 0.46 & Matches dissolution rate \\
\hline$\gamma_{j}$ & 1.1 & 0.45 & 2.44 & Cost of a vacancy \\
\hline$\kappa_{j}$ & 0.0475 & 0.1 & 0.48 & Matching function parameter \\
\hline$\beta_{j}$ & 0.45 & 0.15 & 3 & Workers bargaining power \\
\hline$\tau_{j}$ & $30 \%$ & 0 & - & Tax on labor costs \\
\hline$c_{j}$ & 2.5 & 0.5 & 5 & Entry cost \\
\hline \multicolumn{5}{|c|}{ General parameters } \\
\hline$r$ & & 0.6 & & Discount rate \\
\hline$\sigma$ & & 2.1 & & Elasticity of substitution \\
\hline$\alpha$ & & 0 . & & Utility function parameter \\
\hline$z$ & & 0.1 & & Workers reservation value \\
\hline
\end{tabular}

$\delta_{F}<\delta_{I}$. Labor turnover is higher in the informal sector $d_{F}<d_{I}$. We choose the parameters to be equal to $d_{F}=0.0221$ and $d_{I}=0.0102$ which correspond to an annual rate of $13 \%$ and $30 \%$ as in Heckman and Pagés (2003) and Ulyssea (2009). Finally, making use of equation (8), the exogenous separation rates are set to $s_{F}=0.0062$ and $s_{I}=0.0142$ respectively.

The elasticity of the matching function is set to one half, as usual in the literature (Petrongolo and Pissarides, 2001, Shimer, Rogerson and Wright, 2005) while the scale parameter of the matching function is set to target an unemployment rate of approximatively $12.5 \%$ as in the data (See section 2). According to Camargo (2005) the bargaining power in the informal sector is approximately $1 / 3$ of that in the formal sector. Those parameters can then be set to $\beta_{F}=0.45$ and $\beta_{I}=0.15$, as in Ulyssea (2009). By definition, the labor tax rate is nil in the informal sector and we set the formal tax rate equal to $30 \%$ which is consistent with the value reported in the World Doing Business Indicators for social security contributions and payroll taxes.

Keeping in mind that firms in informal sectors face lower (if any) entry and flow costs $\left(c_{F}>c_{I}\right.$ and $\left.\gamma_{F}>\gamma_{I}\right)$, we set the remaining free parameters so as: (i) to replicate the size of the informal sector; (ii) to get a reasonable wage premium $\left(w_{F}>w_{I}\right)$; (iii) to have a faster (more efficient) matching process informal sectors $\left(m_{F}()<.m_{I}().\right)$; (iv) to have more firms in the informal sector $\left(N_{F}<N_{I}\right)$ but with a lower size $\left(h_{F}>h_{I}\right)$. Baseline parameters are reported in Table 2 . 
Table 3: Main endogenous variables

\begin{tabular}{ccccc}
\hline \hline Variable & \multicolumn{2}{c}{ Sector } & Formal/informal & Description \\
& Formal & Informal & & Wage \\
\hline$w_{j}$ & 0.91 & 0.77 & 1,18 & Labor market tightness \\
$\theta_{j}$ & 0.69 & 2.18 & 0.51 & Number of firms \\
$n_{j}$ & 3.12 & 5.55 & 0.46 & Firm size \\
$h_{j}$ & 0.15 & 0.07 & 2.44 & Elasticity of demand for a firm \\
$\sigma_{j}$ & 6.40 & 11.37 & 0.48 & Profits \\
$\pi_{j}$ & 0.05 & 0.02 & 3 & \\
\hline
\end{tabular}

\section{$5.2 \quad$ Results}

The benchmark results of our numerical exercise are summarized in Table $3 .{ }^{15}$ They match our targets in terms of aggregate variables, with an unemployment rate around $12 \%$ and an informal sector representing $40 \%$ of total employment. Wages are approximately $18 \%$ higher in the formal sector compared to the informal one, which is roughly consistent with the lower bound of estimated wage differentials between the two sectors, as presented in Figure 3, section 2. Almost similar patterns can be found in Bargain and Kwenda (2009) and Tannuri-Pianto and Pianto (2002) for quantile regressions.

The job finding rate is two times larger in the informal than in the formal sector. Although this difference is somewhat larger than the one found in Table 1 of section 2, it is consistent with the viewpoint taken in most existing studies where finding a job in the informal sector is easier than in the formal one (see, e.g. Zenou, 2008, Ulyssea, 2009).

Also consistent with the evidence, there are fewer and larger firms in the formal than in the informal sector as argued by Rauch (1991) and discussed in Tybout (2000). More precisely, we find formal firms to be approximately two times larger than informal ones. Correspondingly, informal firms are approximatively two times more numerous in the informal sector. The resulting price elasticity of demand is around 6 in the formal sector compared to about 11 in the informal one. As a consequence, profits are higher in the formal sector. Having different values for the elasticity is a desirable feature of our model. It implies that the various externalities stemming from market and bargaining powers are of different magnitude across sectors.

\footnotetext{
${ }^{15}$ Figure 13 in Appendix presents a representation of the equilibrium. It certifies that the key IALC condition in equation (32) is monotonic.
} 


\subsection{Short run analysis}

Competition in the formal sector The number of firms in each sector is fixed in the short-run. We first examine the impact of a change in the number of firms in the formal sector on the main variables of the model. With this exercise we are able to understand the effect of an exogenous shock on relative competitiveness between the formal and informal sectors. For each figure, we have depicted two cases: one allowing for overhiring (letting $\frac{\sigma_{j}-\beta_{j}}{\sigma_{j}}<1$, the general case, represented by the continuous line) and the other ruling it out (that is, imposing $\frac{\sigma_{j}-\beta_{j}}{\sigma_{j}}=1$, the dashed line). We first discuss the case with overhiring, and in the next sub-section we compare it to the case with no overhiring.

\section{Figure 6 about here}

Figures 6 and 7 depict how the economy reacts to an exogenous variation of $+/-20 \%$ of the number of firms in the formal sector compared to the baseline case. The effect of an increase in the number of formal firms is unambiguously (i) a fall in unemployment, though this effect is of moderate magnitude, (ii) a marked rise in the relative size of the formal sector in total employment, though (iii) the relative size of each firm in the formal sector tends to decrease. Finally, it can be seen that (iv) each formal firm pays a relatively higher wage compared to the informal sector when competition in the formal sector becomes fiercer.

\section{Figure 7 about here}

These results can be understood by looking at labor market tightnesses and prices. We see that a rise in competition in the formal sector affects tightness in opposite ways across sectors: tightness increases in the formal sector $\left(\theta_{F}\right)$, while it decreases in the informal one $\left(\theta_{I}\right)$. Therefore, this suggests that this is mainly a result of an upward move of the IALC curve in Figure 5, assuming that the IALC relationship is monotonically increasing. This results in a rise in $p_{I}$ and a fall in $p_{F}$, so that the relative price $p_{I} / p_{F}$ goes up. The increase in informal sector relative price explains the fall in relative employment in that sector observed in Figure 6 , since $L_{I} / L_{F}=\left(A_{F} / A_{I}\right)\left(p_{I} / p_{F}\right)^{-\sigma}$, from the PME condition (31). In addition, we see from Figure 7 that this change in relative employment corresponds to a rise in formal sector employment $L_{F}$ and a fall in informal sector employment $L_{I}$.

The decrease in the relative size of formal sector firms corresponds to a fall in firm size in both sectors, as shown in Figure 7. Employment in sector $j$ is equal to $L_{j}=N_{j} \times h_{j}$. In this exercise, the number of firms is fixed in the informal sector. Hence, the fall in sectoral employment $L_{I}$ translates into a decrease in firm size $h_{I}$. For the formal sector, total employment $L_{F}$ rises, but 
so does the number of firms $N_{F}$. The fact that firm size decreases in that sector means that the first effect dominates the latter.

Figure 7 also shows that the change in relative wages corresponds to a rise in wages in both sectors. This is the result of two opposite effects, since $\theta_{F}$ goes up while $\theta_{I}$ goes down. We can therefore conclude that the rise in $\theta_{F}$ induces a rise in both wages, which dominates the negative effect of the fall in $\theta_{I}$.

Overall, if the formal sector were more similar to the informal one in terms of the degree of competition, then aggregate employment would be slightly higher while the informal sector would represent a significantly lower share of total employment. Wages would increase in both sectors, with a relatively larger increase in the informal sector. Firms' profits, however, would be negatively impacted.

The role of wage bargaining externality We now compare the cases with and without overhiring, when there is an increase in the number of formal sector firms. It turns out that : (i) unemployment is lower in the presence of overhiring, compared to the case with no overhiring, as expected. In relative terms, we also see from Figure 6 that the impact of overhiring is larger in the formal sector. (ii) The relative size of the formal sector in total employment is higher, (iii) formal firms are larger and (iv) they pay higher relative wages with overhiring compared to without. Informal firms, on the other hand, are smaller in the presence of overhiring.

These results can be understood by comparing tightnesses and prices with and without overhiring in the previous figures. We see that tightness is larger in the formal sector and lower in the informal sector with overhiring. While the wage bargaining externality studied in sub-section 3.4 takes place in both sectors, it leads to overhiring in the formal sector, but to underhiring in the informal one, as a result of the interplay between the two sectors. Notice that this result contrasts with what would prevail if the two sectors where perfectly identical. Such a case is studied in the appendix where we show that the presence of overhiring would make tightness larger in the two sectors. Those results are similar to those highlighted in Cahuc, Marque and Wasmer (2008) in a model with large firms and an aggregate production function. Our results, however, are driven by simultaneous search in the two sectors rather than by interactions in the aggregate production function.

In terms of the equilibrium representation in Figure 5, the comparison of $\theta_{I}$ and $\theta_{F}$ with and without overhiring suggests that the IALC curve with overhiring is above the one without overhiring. As a result, the price $p_{I}$ is larger with overhiring while the converse is true for $p_{F}$, so that the price ratio $p_{I} / p_{F}$ is higher, leading to a smaller relative size of the informal sector, as depicted in Figure 8. In a nutshell, the so-called overhiring externality leads to higher aggregate 
employment and a lower proportion of informal jobs in total employment.

\subsection{Long run analysis}

Entry costs We now study the long-run impact of a change in entry costs in the formal sector $c_{F}$ on unemployment $u$, the share of informal employment $L_{I} / L_{F}$, relative firms' size $h_{I} / h_{F}$, and relative wages $w_{I} / w_{F}$.

A decrease in formal sector entry costs would decrease the number of formal sector firms in the long-run. Hence, the long-run impacts of decreasing entry costs are very similar qualitatively to the impact of increasing the number of firms in the formal sector studied in the previous subsection. In particular, almost similar patterns for $\theta_{j}$ and $p_{j}$ can be found in the long and in the short run.

\section{Figure 8 about here}

The quantitative effects are, however, not exactly the same. A decrease in the entry costs not only increases the number of firms operating in the formal sector, but also decreases the number of informal firms, though this latter effect is of smaller magnitude. As a result, price elasticities increase for formal sector firms and slightly decrease in the informal sector. This implies that even if the effects do not differ qualitatively between figures 6 and 8, they should be somewhat different in quantitative terms since price elasticities are slightly different. In particular, higher price elasticities in the formal sector also imply smaller profits. The impact is then larger on the formal sector than on the informal one, as can be seen from Figure 9 that shows that relative price elasticity $\sigma_{I} / \sigma_{F}=N_{I} / N_{F}$ is positively related to entry costs.

\section{Figure 9 about here}

There are some noteworthy effects on the labor market. Formal employment increases with lower entry costs in the formal sector, while informal employment and unemployment decrease. From these results, we can conclude that the drop in informality is more than compensated by the rise in formal employment, resulting in lower unemployment. ${ }^{16}$ Finally, changes in sectoral employment also increase firms' size in both sectors. This effect is higher in the informal sector where the number of operating firms decreases.

Overall, it turns out that a decrease in $c_{F}$, due to e.g. a waning in the product market regulation, would lead to lower unemployment and a smaller share of informal jobs in total

\footnotetext{
${ }^{16}$ Notice that while this is true in our numerical exercise, it is not necessarily the case for alternative numerical configurations.
} 
employment. Wages would then be higher in both sectors, with a smaller wage ratio $w_{I} / w_{F}$. As we have seen in section 2, the Brazilian economy has experienced a simultaneous reduction in informality and in unemployment over the past the case. These movements, however, were accompanied by an increase in informal sector relative wages. Hence, a decrease in formal sector entry costs cannot fully account for the pattern of changes of Brazilian variables.

Bargaining power We now study the long-run impact of a change in workers bargaining power in the formal sector $\beta_{F}$ on unemployment $u$, share of informal employment $L_{I} / L_{F}$, relative firms' size $h_{I} / h_{F}$, and relative wages $w_{I} / w_{F}$. Figures 10 and 12 display how the economy reacts to a (quite large) exogenous change of workers' bargaining power in the formal sector, which ranges from 0.35 to 0.55 . The long-run impact of changing workers' bargaining power is a combination of its direct impact and of its impact on the number of firms in each sector in the long-run equilibrium, $N_{I}$ and $N_{F}$. Lower workers' bargaining power increases profits, which, in turn, should lead to a higher number of firms. The effect is larger in the formal sector, as can be seen from Figure 12, where the relative elasticity $\sigma_{I} / \sigma_{F}=N_{I} / N_{F}$ decreases with a lower $\beta_{F}$.

The effect of a decrease in formal workers bargaining power is unambiguously (i) a decrease in unemployment, (ii) a decrease in informal employment relative to formal employment and (iii) a rise in the relative size of informal firms compared to formal firms, and (iv) an increase in relative wages $w_{I} / w_{F}$.

\section{Figure 10 about here}

These results can be understood with the analysis of the impact of $\beta_{F}$ on tightnesses and prices as depicted on Figure 11. A decrease in bargaining power $\beta_{F}$ results in a rise in tightness for both sectors, $\theta_{I}$ and $\theta_{F}$. This suggests an upward shift of the PC curve in Figure 5. This leads to a rise in the price in the informal sector $p_{I}$. The price $p_{F}$, however, decreases despite higher tightness, as a result of the decrease in labor costs due to lower bargaining power of the sector's workers.

\section{Figure 11 about here}

In turn, the relative price $p_{I} / p_{F}$ goes up, which explains the decrease in $L_{I} / L_{F}=\left(A_{F} / A_{I}\right)\left(p_{I} / p_{F}\right)^{-\sigma}$ in Figure 10. Wages decrease in both sectors, in spite of the increase in tightness: the fall in bargaining power more than compensates the rise in tightnesses. As can be inferred from equation (26), $\beta_{F}$ only affects the informal wage through workers' reservation utility while formal wages are also affected directly. It follows that wages decrease by a larger amount in the formal sector, so that relative wages $w_{I} / w_{F}$ increase. 
Note that, as shown in Figure 10, formal sector employment increases when their workers have lower bargaining power. In the informal sector, on the other hand, employment drops with smaller $\beta_{F}$. Unemployment, on its turn, always decreases with lower $\beta_{F}$, meaning that the rise in formal employment is larger than the fall in informal employment. Hence, it appears that the impact of changes in formal employment on unemployment is cushioned by the informal sector. With respect to the number of operating firms, it increases in the formal sector and slightly decreases in the informal sector. This translates in changes in firms' size in each sector as follows. In the formal sector, firms' size $h_{F}$ decreases as a result of the increase in formal employment $L_{F}$ and in the number of operating firms, $N_{F}$, the effect being of a relatively large magnitude. However, firms' size reacts less in the informal sector due to the fact that the number of operating firms in that sector is hardly affected by changes in the bargaining power. It then turns out informal firm's size is slightly decreased. As a result, firms' relative size, $h_{I} / h_{F}$ increases, following a drop in $\beta_{F}$.

\section{Figure 12 about here}

Overall, it turns out that if the formal sector were more similar to the informal one in terms of bargaining power (lower $\beta_{F}$, due to a cutback in labor market regulation, for instance), then unemployment would be lower, and the informal sector would represent a lower share of total employment. Moreover, the wage ratio $w_{I} / w_{F}$ would increase. This set of effects is compatible with the stylized facts observed for the Brazilian economy since 2002: unemployment and informality decreased, while informal sector relative wage increased.

\section{Conclusion}

Using a matching model with large firms similar in spirit to Delacroix (2006) and Ebell and Haefke (2009), we have studied the impact of product and labor market regulations on equilibrium unemployment, the size of formal and informal sectors and wages. Our model endogenously generates a less competitive formal sector, which is a common assumption taken by previous literature. In this setting, we have shown that a fall in PMR strictness (captured by a fall in entry costs in the formal sector) reduces the size of the informal sector and unemployment while it raises wages. Conversely, a fall in LMR (captured by a fall in workers' bargaining power in the formal sector) reduces both unemployment and informality while it reduces wages. For policy purposes, this means that it is possible to reduce informality without diminishing wages by reducing PMR instead of LMR strictness, or by reducing both simultaneously. Notice that, in this case, although wages would increase, wage inequality would increase with the rise in the 
formal sector wage premium. Finally, we consider the effects of wage bargaining in both sectors, which leads to 'overhiring' in the formal sector. This translates into a smaller relative size of the informal sector. 


\section{Technical Appendix}

\subsection{Wage determination}

Substituting equations (17) and (20) into equation (21) we get:

$$
\left(1-\beta_{j}\right) \frac{w_{j}-r U}{r+d_{j}}=\frac{\beta_{j}}{\left(r+d_{j}\right)\left(1+\tau_{j}\right)}\left[A_{j} \frac{\sigma_{j}-1}{\sigma_{j}} p_{j}-\left(w_{j}\left(h_{j}\right)+\frac{\partial w_{j}\left(h_{j}\right)}{\partial h_{j}} h_{j}\right)\left(1+\tau_{j}\right)\right]
$$

or

$$
w_{j}=\left(1-\beta_{j}\right) r U+\frac{\beta_{j}}{1+\tau_{j}}\left[A_{j} \frac{\sigma_{j}-1}{\sigma_{j}} p_{j}-\frac{\partial w_{j}\left(h_{j}\right)}{\partial h_{j}} h_{j}\left(1+\tau_{j}\right)\right]
$$

or

$$
\frac{\partial w_{j}\left(h_{j}\right)}{\partial h_{j}}+\frac{1}{\beta_{j} h_{j}} w_{j}-\frac{\left(1-\beta_{j}\right) r U+\beta_{j} \frac{\sigma_{j}-1}{\sigma_{j}\left(1+\tau_{j}\right)} p_{j} A_{j}}{\beta_{j} h_{j}}=0
$$

which defines the wage $w_{j}$ as a solution to a differential equation of the form $\frac{\partial w_{j}}{\partial h_{j}}+F\left(h_{j}\right) w_{j}\left(h_{j}\right)+$ $G\left(h_{j}\right)=0$, with $F\left(h_{j}\right)=\frac{1}{\beta_{j} h_{j}}$ and $G\left(h_{j}\right)=-\frac{\left(1-\beta_{j}\right) r U+\beta_{j} \frac{\sigma_{j}-1}{\sigma_{j}\left(1+\tau_{j}\right)} p_{j} A_{j}}{\beta_{j} h_{j}}$. Equation (39) admits as a solution

$$
w_{j}\left(h_{j}\right)=\left[K-\int_{0}^{h_{j}} \frac{G(\zeta)}{H(\zeta)} d \zeta\right] H\left(h_{j}\right)
$$

where $H($.$) solves the homogeneous equation d H / d h_{j}+F\left(h_{j}\right) H\left(h_{j}\right)=0$ which can be rewritten

$$
\frac{d H / d h_{j}}{H\left(h_{j}\right)}=-F\left(h_{j}\right) \text { or } h_{j} \frac{d H / d h_{j}}{H\left(h_{j}\right)}=-1 / \beta_{j}
$$

Thus

$$
H\left(h_{j}\right)=h_{j}^{-1 / \beta_{j}}
$$

As in Cahuc and Wasmer (2001), we assume the wage $w_{j}$ is bounded at $h_{j}=0$, which implies $K=0$ in equation (40). $w_{j}$ can then be rewritten as:

$$
\begin{aligned}
w_{j}\left(h_{j}\right) & =h_{j}^{-1 / \beta_{j}} \int_{0}^{h_{j}} \zeta^{1 / \beta_{j}-1}\left[\frac{\left(1-\beta_{j}\right)}{\beta_{j}} r U+\frac{\sigma_{j}-1}{\sigma_{j}\left(1+\tau_{j}\right)} p_{j}(\zeta) A_{j}\right] d \zeta \\
& =\left(1-\beta_{j}\right) r U+\beta_{j} \frac{\sigma_{j}-1}{\sigma_{j}\left(1+\tau_{j}\right)} h_{j}^{-1 / \beta_{j}} A_{j} \int_{0}^{h_{j}} \zeta^{1 / \beta_{j}-1} p_{j}(\zeta) d \zeta
\end{aligned}
$$

Integrating by parts and using the fact that $d p_{j} / d \zeta=-p_{j} / \sigma_{j} \zeta$ according to equation (3), so that $\int_{0}^{l_{j}} \zeta^{1 / \beta_{j}-1} p_{j}(\zeta) d \zeta=\frac{\sigma_{j} \beta_{j}}{\sigma_{j}-\beta_{j}} h_{j}^{1 / \beta_{j}} p_{j}\left(h_{j}\right)$. This leads to equation (23):

$$
w_{j}\left(h_{j}\right)=\left(1-\beta_{j}\right) r U+\beta_{j} \frac{\sigma_{j}-1}{\sigma_{j}-\beta_{j}} \frac{A_{j} p_{j}\left(h_{j}\right)}{\left(1+\tau_{j}\right)} .
$$

\subsection{Summary of equilibrium relationships}

\subsubsection{Short-run equilibrium}

A short-run equilibrium is defined as a tuple $\left(r U^{*}, p_{j}^{*}, w_{j}^{*}, L_{j}^{*}, u^{*}, \theta_{j}^{*}, v_{j}^{*}, h_{j}^{*}, C_{j}^{*}, Y^{*}\right)$, with $j=I, F$, for a given value of $N_{j}$ for each industry. 
Workers' Reservation wage.

$$
r U^{*}=z+\sum_{j=F, I} \frac{1}{1+\tau_{j}} \frac{\beta_{j}}{1-\beta_{j}} \frac{\gamma_{j} \theta_{j}^{*}}{1-\delta_{j}}
$$

Prices.

$p_{j}^{*} \equiv p_{j}\left(\theta_{j}^{*}, \theta_{k}^{*}\right)=\frac{\sigma_{j}-\beta_{j}}{\sigma_{j}-1} \frac{1}{A_{j}}\left[\left(1+\tau_{j}\right) z+\frac{1+\tau_{j}}{1+\tau_{k}} \frac{\beta_{k}}{1-\beta_{k}} \frac{\gamma_{k} \theta_{k}^{*}}{1-\delta_{k}}+\frac{r+d_{j}+\beta_{j} \theta_{j}^{*} m_{j}\left(\theta_{j}\right)}{\left(1-\beta_{j}\right)\left(1-\delta_{j}\right)} \frac{\gamma_{j}}{m_{j}\left(\theta_{j}^{*}\right)}\right]$

Wages.

$$
w_{j}^{*} \equiv w_{j}\left(\theta_{j}^{*}, \theta_{k}^{*}\right)=z+\frac{\beta_{j}}{1-\beta_{j}} \frac{\gamma_{j}\left(r+d_{j}+\theta_{j}^{*} m_{j}\left(\theta_{j}^{*}\right)\right)}{\left(1-x_{j}\right) m_{j}\left(\theta_{j}^{*}\right)\left(1+\tau_{j}\right)}+\frac{1}{1+\tau_{k}} \frac{\beta_{k}}{1-\beta_{k}} \frac{\gamma_{k} \theta_{k}^{*}}{1-\delta_{k}}
$$

for $j \in\{I, F\}$ and $k \neq j$. Aggregate Price Index.

$$
P^{*}=1=\left[\alpha p_{I}^{* 1-\sigma}+\alpha p_{F}^{* 1-\sigma}\right]^{1 /(1-\sigma)}
$$

\section{Labor Market Flow Equilibrium.}

$$
\begin{aligned}
L_{j}^{*} & =\left[1+\frac{d_{j}}{\theta_{j}^{*} m\left(\theta_{j}^{*}\right)}+\frac{d_{j}}{d_{k}} \frac{\theta_{k}^{*} m_{k}\left(\theta_{k}^{*}\right)}{\theta_{j}^{*} m_{j}\left(\theta_{j}^{*}\right)}\right]^{-1}, \text { for } j=F, I, \\
u^{*} & =1-L_{F}^{*}-L_{I}^{*} \\
v_{j}^{*} & =\theta_{j}^{*} u^{*}
\end{aligned}
$$

Firms' size.

$$
h_{j}^{*}=L_{j}^{*} / N_{j} \equiv h_{j}\left(\theta_{j}^{*}, \theta_{k}^{*}\right)
$$

where $j \in\{I, F\}$ and $k \neq j$, and where $N_{j}$ can be treated as a parameter in the short run, and will be endogenized in the longer run.

Product Market equilibrium.

$$
C_{j}^{*}=\left(p_{j}^{*}\right)^{-\sigma} \alpha Y^{*}=A_{j} L_{j}^{*}
$$

Aggregate Income.

$$
Y^{*}=\sum_{j=I, F} A_{j} p_{j}\left(\theta_{j}^{*}, \theta_{k}^{*}\right) L_{j}\left(\theta_{j}^{*}, \theta_{k}^{*}\right) .
$$

\subsubsection{Long-run equilibrium}

The next step is to determine the equilibrium number of firms in each industry. We have : Sectoral elasticities.

$$
\sigma_{j}^{*}=\sigma N_{j}^{*}
$$




\section{Free entry.}

$$
c_{j}+\frac{\gamma_{j} h_{j}^{*}}{m_{j}\left(\theta_{j}^{*}\right)}=\frac{1+r}{r+\delta_{j}} \pi_{j}^{*}
$$

Firms' profits.

$$
\begin{aligned}
\pi_{j}^{*} & =p_{j}^{*} A_{j} h_{j}^{*}-w_{j}^{*} h_{j}^{*}\left(1+\tau_{j}\right)-\gamma_{j} v_{j}^{*} \\
& =p_{j}^{*} A_{j} h_{j}^{*}-w_{j}^{*} h_{j}^{*}\left(1+\tau_{j}\right)-\gamma_{j} s_{j} h_{j}^{*} / m_{j}\left(\theta_{j}^{*}\right)
\end{aligned}
$$

\subsection{A particular case: identical sectors}

It makes sense to determine how the economy would behave in the absence of differences between the formal and the informal sector, that is, if there were only one sector in the economy. This symmetric case can serve as a reference point to be compared to the case studied in our paper, where there are two different sectors.

In the symmetric case, we have $p_{j}^{*}=p_{k}^{*}=1, \theta_{j}^{*}=\theta_{k}^{*}=\theta^{*}$ and $L_{j}^{*}=L_{k}^{*}=L^{*}$, which makes the model particularly simple to study. From equation (29), labor market tightness $\theta^{*}$ is implicitly defined by:

$$
A=\frac{\sigma N-\beta}{\sigma N-1}\left[(1+\tau) z+\frac{\beta}{1-\beta} \frac{\gamma \theta^{*}}{1-\delta}+\frac{1}{1-\beta} \frac{r+d+\beta \theta^{*} m\left(\theta^{*}\right)}{1-\delta} \frac{\gamma}{m\left(\theta^{*}\right)}\right] .
$$

By applying the implicit function theorem to equation (52) we carry out a number of comparative statics which are described below.

Effect of a rise in competition $N$ on wages, tightness and (un)employment. From equation (52), the short-run impact of increasing competition is unambiguously a rise in $\theta^{*}$. In turn, this implies a rise in employment $L^{*}=\frac{2 \theta^{*} m\left(\theta^{*}\right)}{2 \theta^{*} m\left(\theta^{*}\right)+d}$ and a decrease in unemployment $u^{*}=$ $\frac{d}{2 \theta^{*} m\left(\theta^{*}\right)+d}$. However, this is the result of two opposite effects, as the term $\frac{\sigma N-\beta}{\sigma N-1}$ in equation (52) can itself be decomposed in two terms: (i) $N$ reduces the markup factor $\frac{\sigma N}{\sigma N-1}$ while (ii) it increases the overhiring factor $\frac{\sigma N-\beta}{\sigma N}$. According to (i), more competition leads to lower markup, higher output and lower unemployment. According to (ii), overhiring is positively related to market power. A rise in $N$ thus reduces incentives to overhire, and thus tends to increase wages, which is detrimental to employment. It is straightforward to show that the former effect always dominates the latter so that employment increases when market power decreases.

Effect of a rise in workers' bargaining power $\beta$. The short-run impact of raising workers' bargaining power $\beta$ on tightness is a priori ambiguous. This is the result of two opposite effects: (i) a rise in $\beta$ translates into higher labor costs (the term in brackets in equation (52)) which reduces tightness $\theta^{*}$. However, (ii) a rise in $\beta$ increases firms incentives to overhire, which counteracts (i). It is possible to show that $\partial \theta / \partial \beta \gtreqless 0$ whenever

$$
\sigma \frac{<}{>} \frac{(1+\tau) z+\frac{1}{1-\beta} \frac{r+d+2 \beta \theta^{*} m\left(\theta^{*}\right)}{1-\delta} \frac{\gamma}{m\left(\theta^{*}\right)}+\beta \frac{r+d+2 \theta^{*} m\left(\theta^{*}\right)}{(1-\delta)(1-\beta)^{2}} \frac{\gamma}{m\left(\theta^{*}\right)}}{\frac{r+d+2 \theta^{*} m\left(\theta^{*}\right)}{(1-\delta)(1-\beta)^{2}} \frac{\gamma}{m\left(\theta^{*}\right)}}
$$


For low levels of $\sigma$ (low competition), a rise in $\beta$ raises firms' incentives to overhire. As a result, $\theta^{*}$ and $L^{*}$ should increase. For larger levels of $\sigma$, a rise in workers' bargaining power $\beta$ raises labor costs and this leads to a fall in $\theta^{*}$ and $L^{*}$.

Effect of a rise in $\tau, z, \gamma$. The short-run impact of a rise in $\tau, z$ and $\gamma$ is lower tightness and lower employment. From (52), those three parameters increase wage or search costs for firms, which leads to a fall in tightness and employment. On the other hand, the short run impact of a rise in productivity is higher tightness and higher employment.

Effect of the overhiring factor $\frac{\sigma N-\beta}{\sigma N}$. In the absence of bargaining externalities, the overhiring factor $\frac{\sigma N-\beta}{\sigma N}$ in equation (52) would be equal to one, and the resulting equilibrium tightness $\theta_{\text {noovh }}$ would solve :

$$
A=\frac{\sigma N}{\sigma N-1}\left[(1+\tau) z+\frac{\beta}{1-\beta} \frac{\gamma \theta_{\text {noovh }}}{1-\delta}+\frac{1}{1-\beta} \frac{r+d+\beta \theta_{\text {noovh }} m\left(\theta_{\text {noovh }}\right)}{1-\delta} \frac{\gamma}{m\left(\theta_{\text {noovh }}\right)}\right]
$$

A comparison of (53) and (52) implies that $\theta^{*} \geq \theta_{\text {noovh }}$. This also implies that $w\left(\theta^{*}\right) \geq$ $w\left(\theta_{\text {noovh }}\right)$, and that $L^{*} \geq L_{\text {noovh }}$. That is, tightness, wages and employment are higher in the presence of the overhiring externality.

\subsection{Uniqueness of equilibrium}

\section{Step 1. Properties of the price functions (42).}

$$
p_{j}=\frac{\sigma_{j}-\beta_{j}}{\sigma_{j}-1} \frac{1}{A_{j}}\left[\left(1+\tau_{j}\right) z+\frac{1+\tau_{j}}{1+\tau_{k}} \frac{\beta_{k}}{1-\beta_{k}} \frac{\gamma_{k} \theta_{k}}{1-\delta_{k}}+\frac{1}{1-\beta_{j}} \frac{r+d_{j}+\beta_{j} \theta_{j} m_{j}(\theta)}{1-\delta_{j}} \frac{\gamma_{j}}{m_{j}\left(\theta_{j}\right)}\right]
$$

From the implicit function theorem, we get that $p_{j}$ is increasing in $\theta_{j}$ and $\theta_{k}$.

\section{Step 2. Properties of the Product Market Equilibrium condition (PME).}

Combining (48) and (42) we get

$$
\frac{L_{I}}{L_{F}}=\frac{A_{F}}{A_{I}}\left[\frac{p_{I}\left(\theta_{I}, \theta_{F}\right)}{p_{F}\left(\theta_{I}, \theta_{F}\right)}\right]^{-\sigma}
$$

The properties of the PME curve then results from the implicit function theorem. Differentiating (55) we get that the ratio $\frac{L_{I}}{L F}$ increases with $\theta_{I}$ if the following condition on price elasticities is fulfilled:

$$
\theta_{I} \frac{\partial p_{F} / \partial \theta_{I}}{p_{F}} \geq \theta_{I} \frac{\partial p_{I} / \partial \theta_{I}}{p_{I}}
$$

Similarly, the ratio $\frac{L_{I}}{L F}$ decreases with $\theta_{F}$ if the following condition on price elasticities holds:

$$
\theta_{F} \frac{\partial p_{F} / \partial \theta_{F}}{p_{F}} \leq \theta_{F} \frac{\partial p_{I} / \partial \theta_{F}}{p_{I}}
$$


If these two conditions are not fulfilled, then the PME curve is not necessarily monotonic in the $\left(\theta_{F}, \theta_{I}\right)$ space. Nevertheless, our simulations indicate that this is the case.

Step 3. Properties of the labor Market Flow Equilibrium condition (LME).

$$
\frac{L_{I}}{L_{F}}=\frac{d_{F}}{d_{I}} \frac{\theta_{I} m_{I}\left(\theta_{I}\right)}{\theta_{F} m_{F}\left(\theta_{F}\right)}
$$

The RHS of (58) is decreasing in $\theta_{F}$ and increasing in $\theta_{I}$. Therefore, the (LME) curve is upward sloping in the $\left(\theta_{F,} \theta_{I}\right)$ space.

\section{Step 4. Properties of the IAL curve.}

Using LME and PME, we get the following IAL relationship:

$$
\frac{d_{F}}{d_{I}} \frac{\theta_{I} m_{I}\left(\theta_{I}\right)}{\theta_{F} m_{F}\left(\theta_{F}\right)}=\frac{A_{F}}{A_{I}}\left[\frac{p_{I}\left(\theta_{I}, \theta_{F}\right)}{p_{F}\left(\theta_{I}, \theta_{F}\right)}\right]^{-\sigma}
$$

which implicitly defines $\theta_{I}$ as a function of $\theta_{F}$. From step 2, we know that the LHS of equation (59) is not necessarily monotonic. Here, again, our simulations indicate that this is the case.

\section{Step 5. Properties of the PC curve.}

Using (29), the definition of the aggregate price index, $P^{*}=\alpha^{1 /(1-\sigma)}\left[p_{I}\left(\theta_{I}, \theta_{F}\right)^{1-\sigma}+p_{F}\left(\theta_{I}, \theta_{F}\right)^{1-\sigma}\right]^{1 /(1-\sigma)}$, and the normalization $P^{*}=1$, the $\mathrm{PC}$ relationship can be written :

$$
1-\alpha p_{I}\left(\theta_{I}, \theta_{F}\right)^{1-\sigma}=\alpha p_{F}\left(\theta_{I}, \theta_{F}\right)^{1-\sigma}
$$

Given the properties of prices studied in step 1, this equation implicitly defines a decreasing relationship between $\theta_{I}$ and $\theta_{F}$.

\section{Step 6. Properties of the equilibrium.}

An equilibrium is the pair $\left(\theta_{I}^{*}, \theta_{F}^{*}\right)$ at the intersection of the IAL and PC curves studied in steps (4) and (5). The figure below illustrates the benchmark where an upward sloped IAL curve and an downward sloped PC establish the equilibrium.

\section{Figure 13 about here}

Comparative statics properties of the equilibrium result from shifts of these curve, and they are studied numerically. 

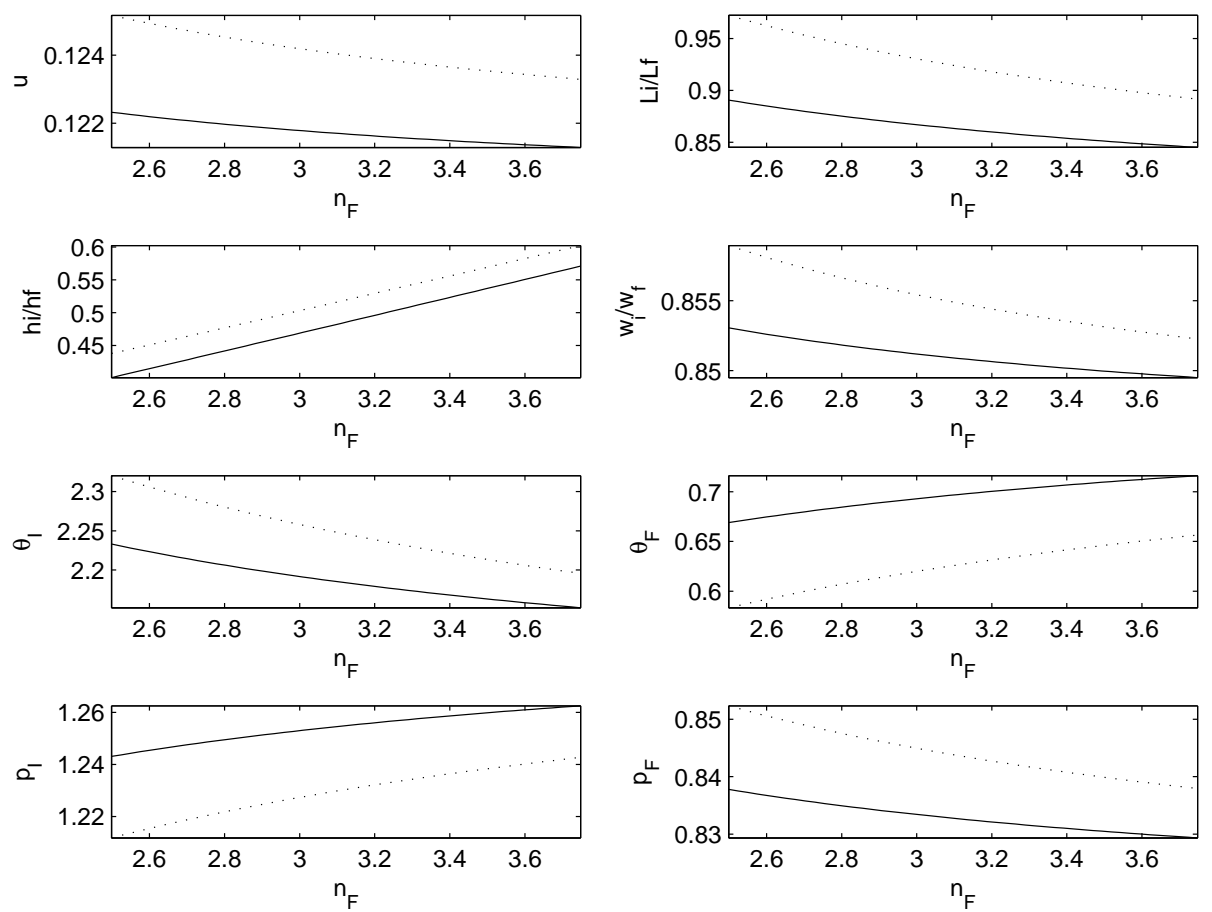

Figure 6: The short-run impact of varying competition. Continuous lines refers to the case where the overhiring externality is taken into account whiled dashed lines refers to the case where the externality is ruled out. 

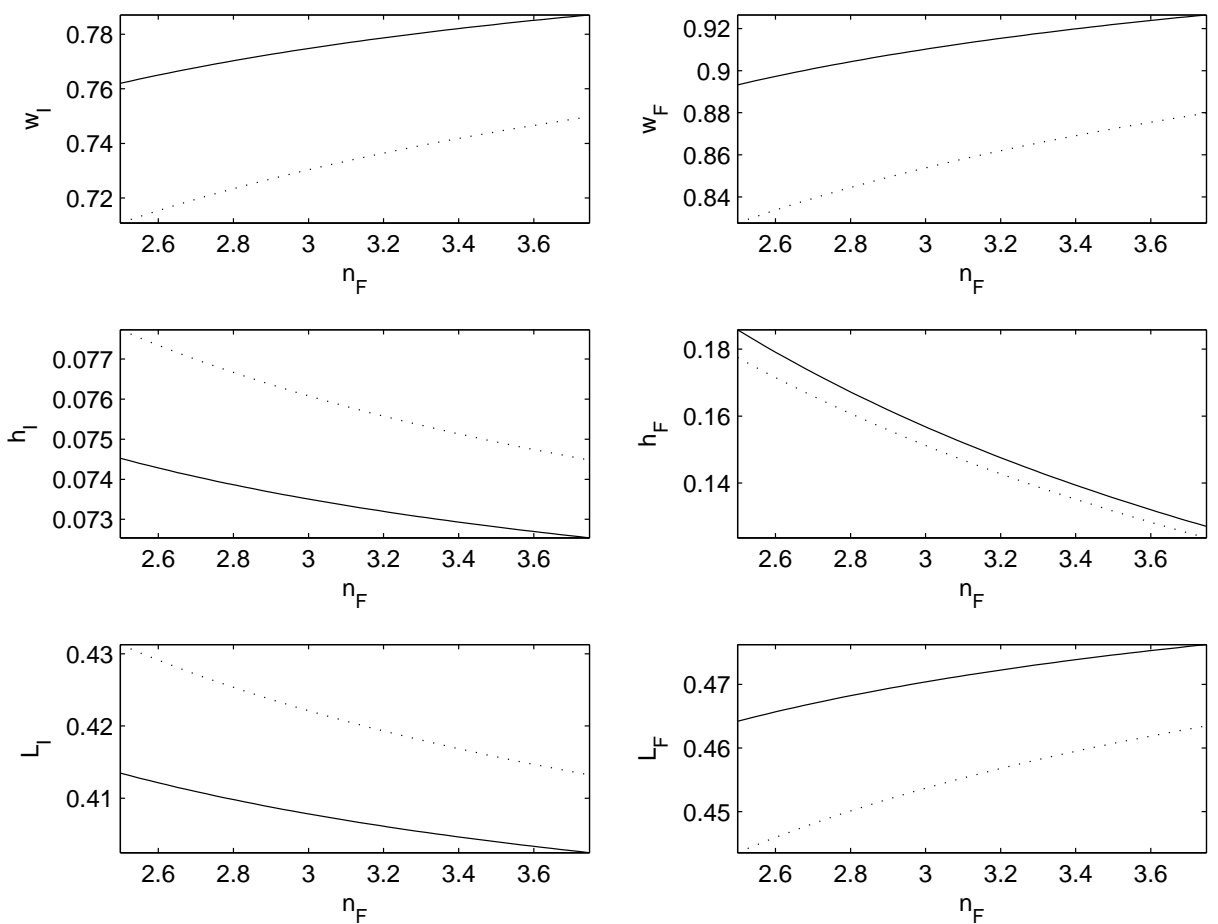

Figure 7: The short-run impact of varying competition (cont'd). Continuous lines refers to the case where the overhiring externality is taken into account whiled dashed lines refers to the case where the externality is ruled out.
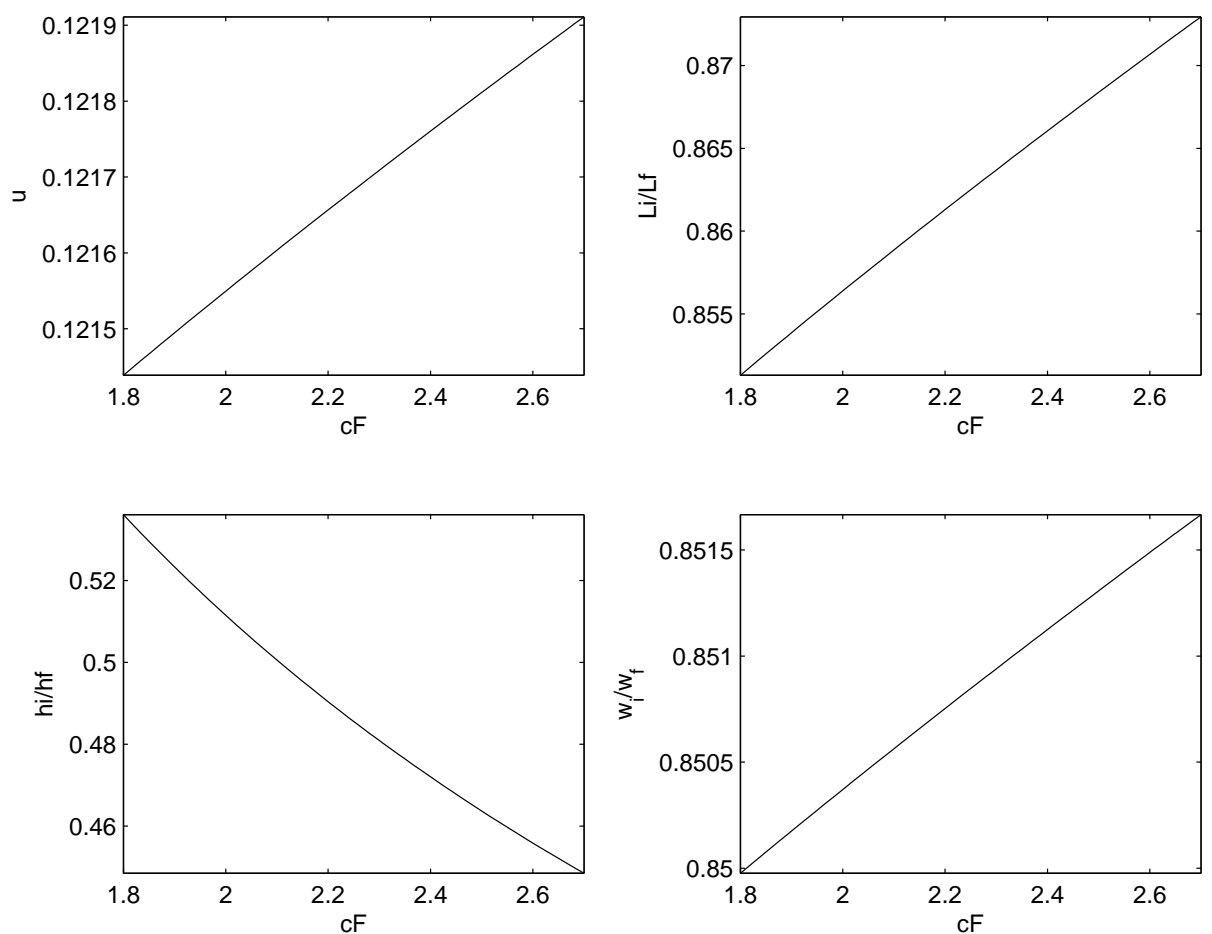

Figure 8: The long-run impact of varying barriers to entry in the formal sector 


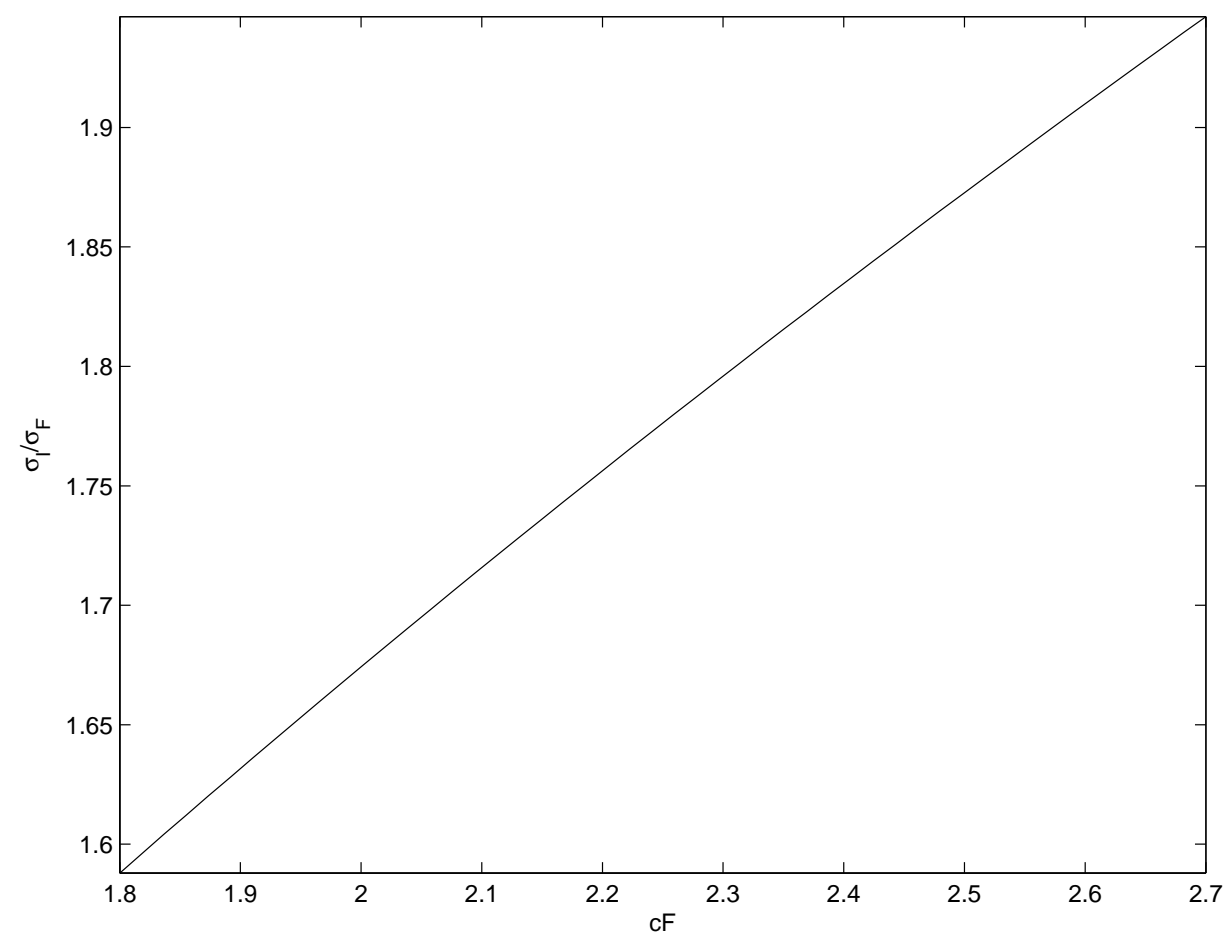

Figure 9: The long-run impact of varying barriers to entry in the formal sector (cont'd)
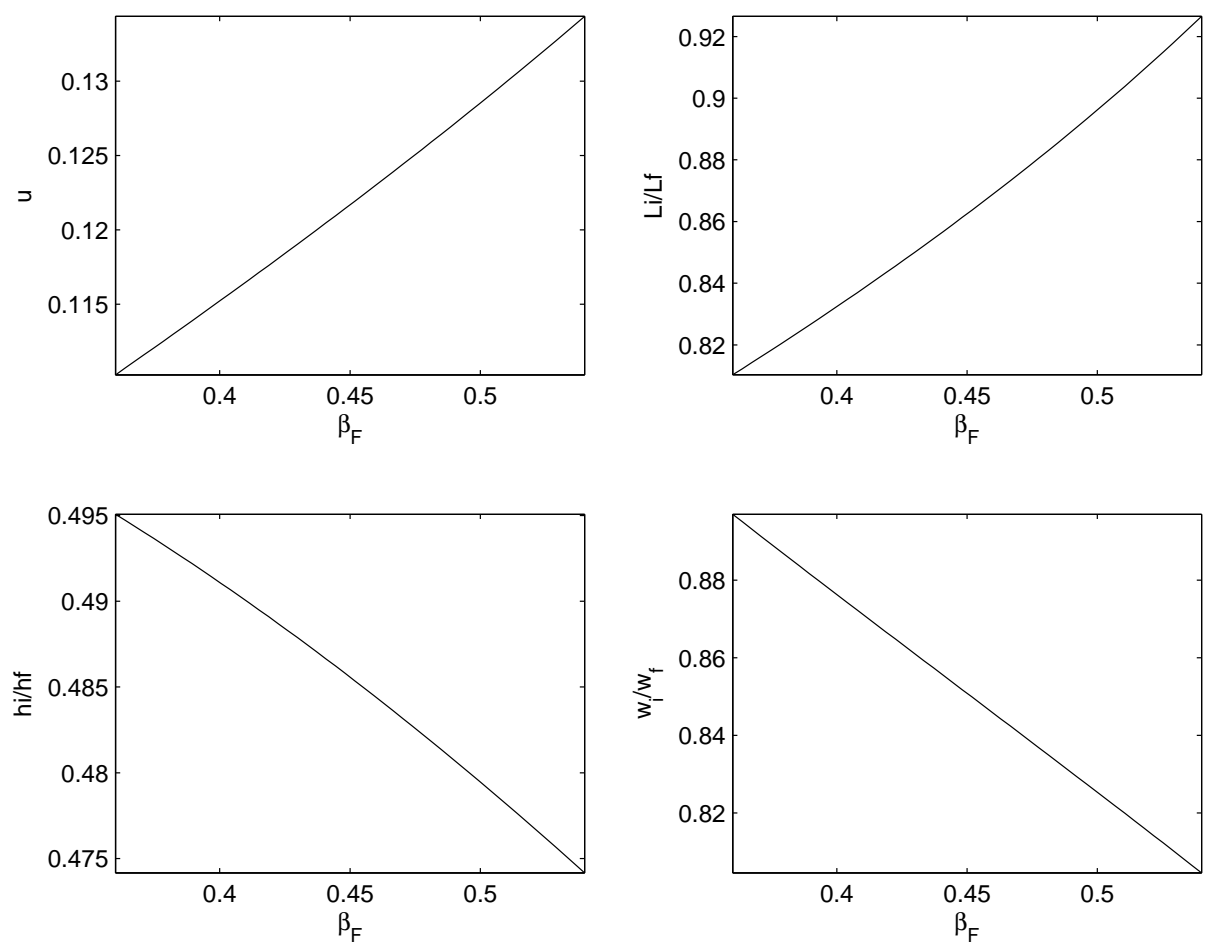

Figure 10: The long-run impact of varying bargaining power in the formal sector 

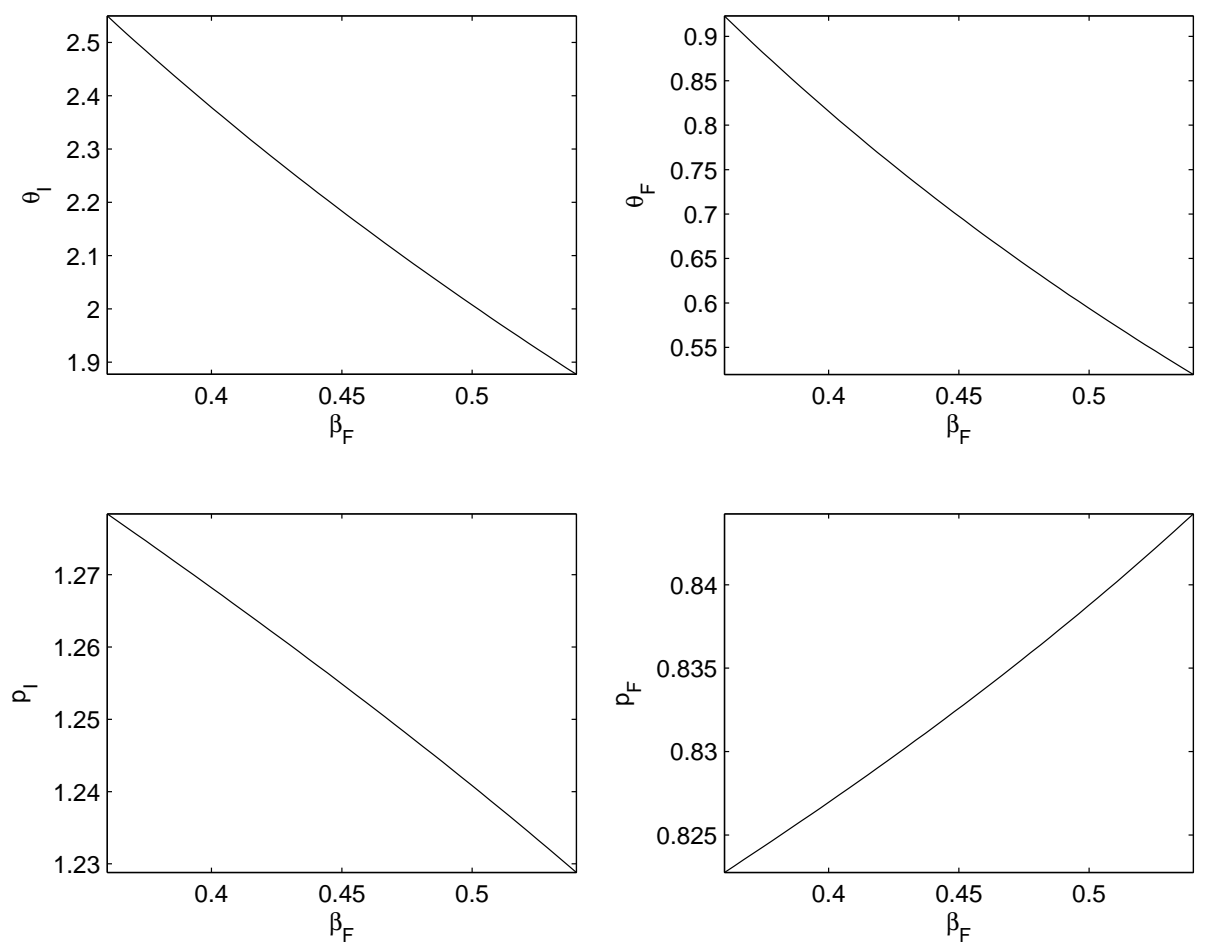

Figure 11: The long-run impact of varying bargaining power in the formal sector (cont'd)

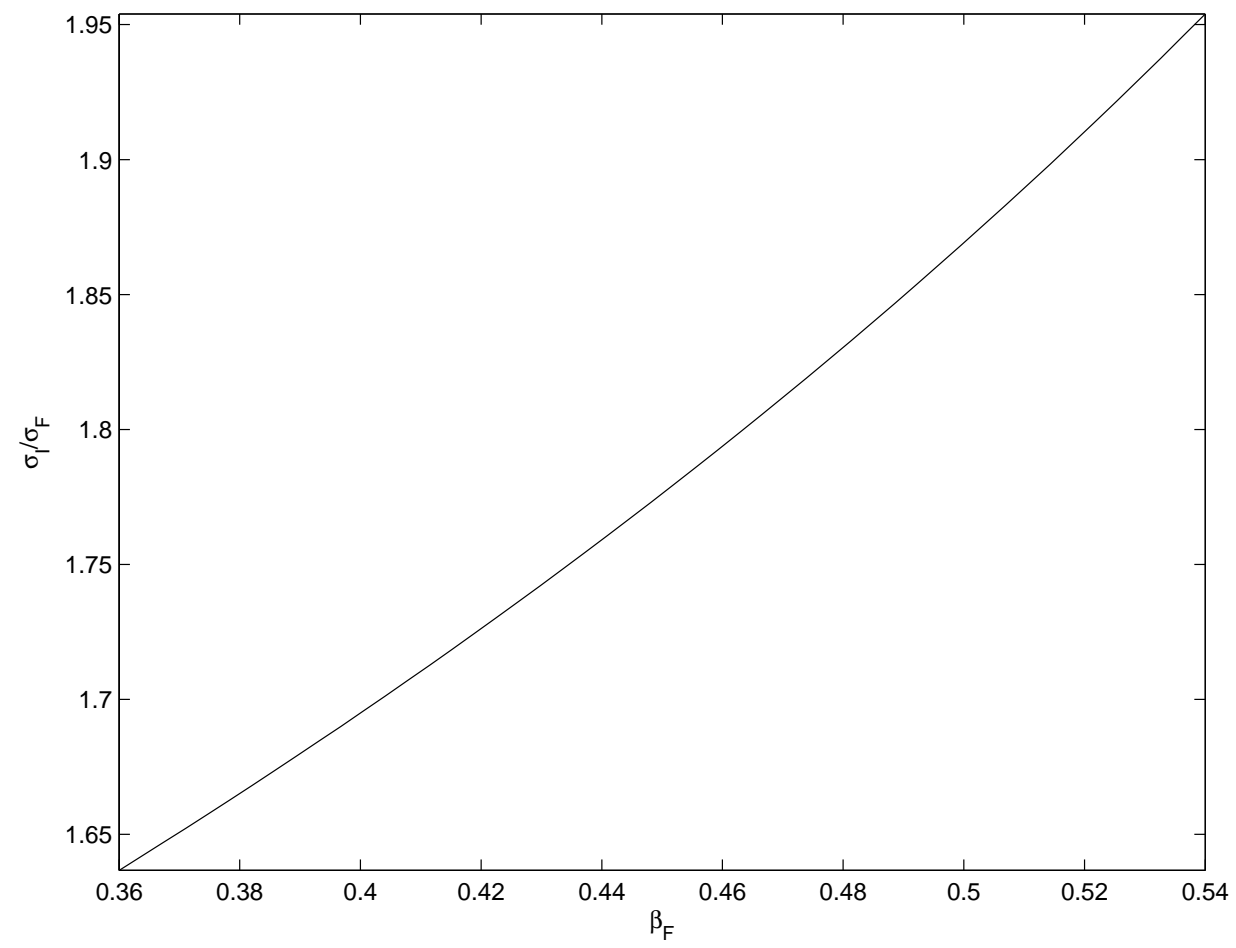

Figure 12: The long-run impact of varying bargaining power in the formal sector (cont'd) 


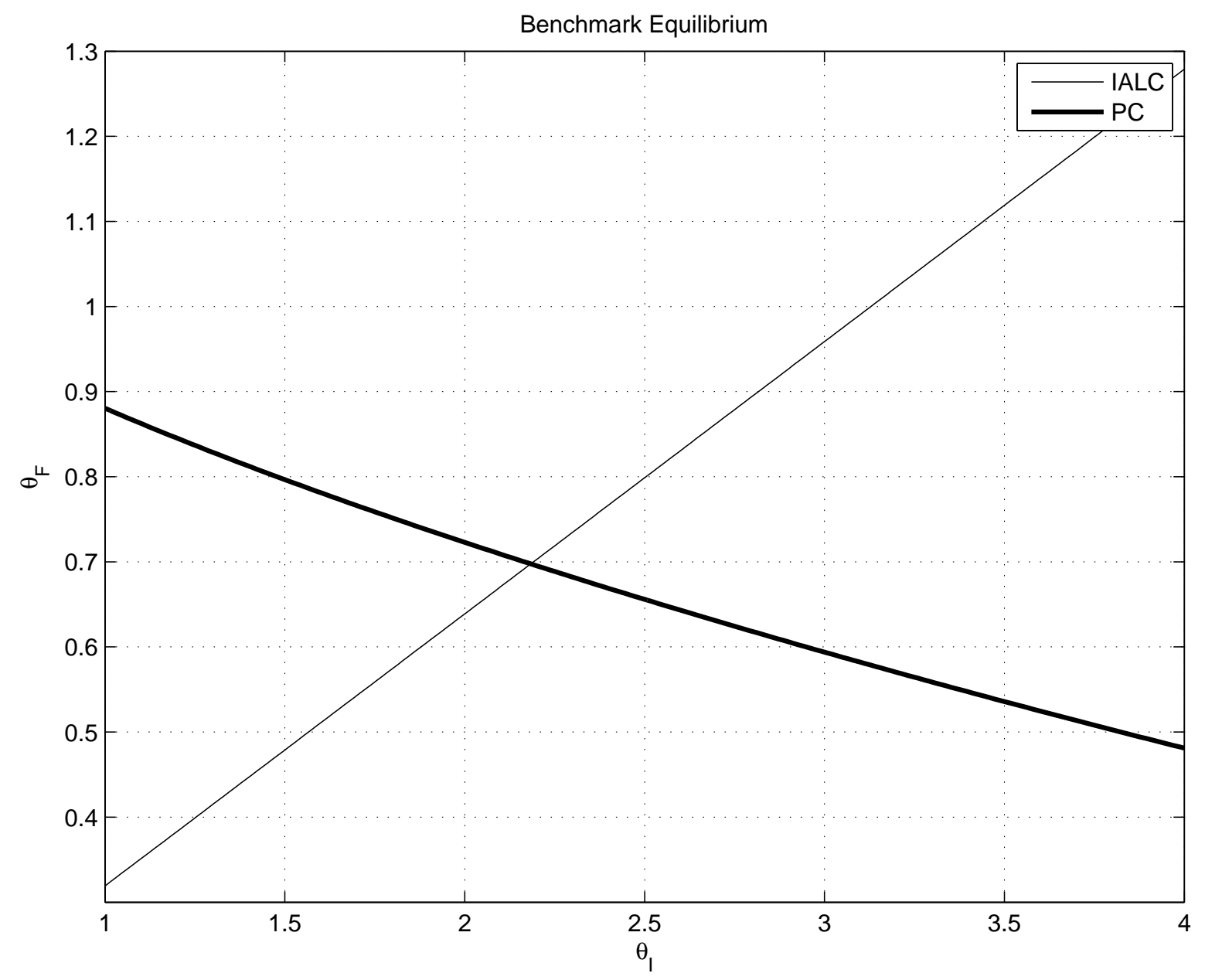

Figure 13: Equilibrium in the benchmark case 